\title{
Study on the influencing factors of the deformation in the process of gear shaping
}

Xiuxu Zhao ( $\square$ zhaoxiuxu@whut.edu.cn )

Wuchang University of Technology

Qingzhuang Liu

Yu Fu

Peng Chen

\section{Research Article}

Keywords: 42CrMo gear steel, gear shaping, finite element simulation, cutting deformation

Posted Date: March 12th, 2021

DOl: https://doi.org/10.21203/rs.3.rs-282845/v1

License: (c) (i) This work is licensed under a Creative Commons Attribution 4.0 International License.

Read Full License

Version of Record: A version of this preprint was published at The International Journal of Advanced Manufacturing Technology on July 27th, 2021. See the published version at https://doi.org/10.1007/s00170-021-07702-2. 


\title{
Study on the influencing factors of the deformation in the process of gear shaping
}

\author{
Xiuxu Zhao ${ }^{1,2, a}$, Qingzhuang $\mathrm{Liu}^{1,2}$,Yu Fu${ }^{1,2}$,Peng Chen ${ }^{1,2}$ \\ School of Mechanical \& Electronic, Wuhan University of Technology, Wuhan, 430070 China \\ Hubei Key Laboratory of Digital Manufacturing, Wuhan, 430070 China \\ zhaoxiuxu@whut.edu.cn
}

\begin{abstract}
Ring gear is an important part of high-power transmission system. Because of its thin wall and low stiffness, it is easy to produce deformation in the process of gear shaping, which affects its accuracy. In order to ensure the machining quality of gear shaper, this research focuses on the typical material $42 \mathrm{CrMo}$, which is used in the gear ring of automobile gearbox. Through the finite element simulation and actual test, the influence of gear shaper cutting parameters on the deformation of gear ring is studied. The results show that the influence of the main cutting parameters on the deformation of the ring gear is in the order of radial feed, circumferential feed, stroke speed and cutting depth. In the actual gear shaping process, the cutting parameters can be adjusted according to the deformation law of $42 \mathrm{CrMo}$ workpiece in the gear shaping process, so as to control the deformation of gear ring.
\end{abstract}

Keywords:42CrMo gear steel; gear shaping; finite element simulation; cutting deformation

\section{Introduction}

Ring gear is an important part of high-power transmission system, which has the characteristics of high working speed and large load. Therefore, higher requirements are put forward for the selection of workpiece materials and processing technology. A typical feature of ring gear is that its wall thickness is quite different from the radial and axial dimensions, so it is a typical weak stiffness component.

In the gear shaping process, the gear shaping cutter and the workpiece are usually matched according to the modulus and pressure angle. At the same time, the gear shaping knife reciprocates while the two are purely meshing without gaps. The gear shaper processing diagram of the gear ring is shown in Fig. 1. It mainly includes the gear shaper cutter moving up and down along the main axis to cut the chips from the workpiece; in order to avoid scratching the machined surface, damaging the tool tip of the gear shaper cutter and reducing the wear of the gear shaper cutter, the workpiece or the gear shaper cutter needs to do cutter relieving motion; The circumferential feed motion of gear shaper cutter means that when the gear shaper cutter makes cutting motion, it rotates around the axis of cutter shaft to continuously process the new metal layer on the workpiece; Every time the gear shaper cutter does reciprocating movement, it needs to move a certain distance towards the root until the whole tooth height is cut out; after the gear shaper cutter completes a reciprocating cutting motion, in order to process all the teeth on the gear blank, it must make the worktable drive the gear blank to rotate along the axis, so as to complete the generating movement of the involute profile or the processing of other common gradient curves. 

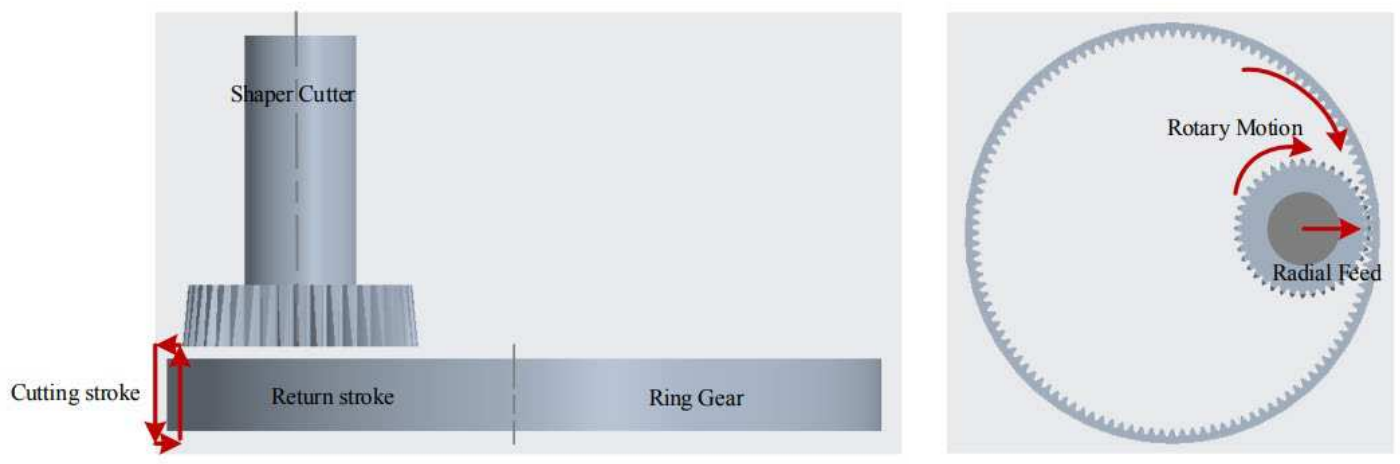

Fig.1 Schematic diagram of gear ring gear shaping

In the process of gear shaping, because of its thin wall thickness and low stiffness, it is easy to produce deformation and even scrap parts under the influence of cutting force, cutting heat, residual stress, clamping force, machine vibration and other factors[1]. To solve this problem, the current research mainly focuses on the influence of cutting force, clamping deformation, residual stress, and the coupling of cutting force and cutting heat on the machining deformation of weak stiffness structural parts. For example, Liu Xuejie established the cutting force model based on the cutting layer area by analyzing and processing the cutting test data of ZL114A aluminum alloy, and studied the cutting force modeling and deformation prediction[2]. In order to solve the problem that thin-walled parts have low tolerance to cutting force and cutting heat, and are easy to produce machining deformation, Cao Boran established the mathematical model between cutting parameters and cutting force and cutting heat, and obtained the optimal processing parameter combination scheme through the optimization of multi-step cutting parameters[3]. The influence of cutting speed, feed rate and cutting depth on the cutting temperature was analyzed through the thermal mechanical coupling model, and the deformation of the ring gear was compared under the conditions of considering the temperature field and not considering the temperature field. It was found that the cutting heat would increase the deformation of the ring gear, but the deformation of the ring gear would decrease when the temperature rose to a certain range, the influence of shape is limited[4].

According to the tooth profile error and deformation results in the gear profile inspection report after ring gear processing, Wang Jing found that the main error factor was improper clamping mode. The deformation caused by the existing clamping mode was analyzed by using caskilyano theorem, virtual displacement principle and unit load method, and the fixture was redesigned accordingly[5]. V.García Navas and O.Gonzalo et.al. studied the effect of forging and different thermal treatments (normalizing, quenching and tempering), i.e., the effect of different steps of the manufacturing of gears, on the final residual stress state, microstructure and hardness of AISI 4140 steel. The results show that banded ferrite-pearlite structures, and in general chemically inhomogeneous structures, react non uniformly to elevated temperatures during forging and/or subsequent heat treatment processes, affecting the final stress state (plastic deformation is required to accommodate dissimilar thermal expansion behavior for each phase) and consequently leading to distortions. These unpredicted distortions are one 
of the major causes of rejected components and components that need to be reworked[6]. Qiang Kang analyzed the influence of tool flank wear on cutting force, cutting heat and residual stress on the machined surface of $20 \mathrm{Cr} 2 \mathrm{Ni} 4$ alloy steel ring gear by numerical model solving, finite element simulation and experimental research. The results show that the tool wear will change the force and heat in the cutting process, thus affecting the distribution of residual stress on the machined surface[7].

Currently, there are many researches on the optimization of hobbing parameters, but few on the optimization of gear shaping parameters. In a recently published research paper[8], the problem of tooth profile accuracy in bevel gear machining is selected, and the material of the workpiece in this study is 20Cr2Ni4A. The process of gear shaping with different machining parameters was simulated by ABAQUS, and the cutting force distribution cloud diagram during the process of gear shaping was obtained. The simulation results show that when the cutting speed of gear shaper is low, the influence of cutting speed on cutting force is great; when the cutting speed is increased, the influence of cutting speed on cutting force is small. In the process of machining, the feed rate has more influence on the cutting force. Under the same processing parameters, the cutting force increases with the increase of the back feed, and the increase range is larger; when the circumferential feed increases, the cutting force decreases relatively; the influence of the circumferential feed on the cutting force is smaller than that of the back feed. According to the simulation analysis of the ring gear shaping processing parameters, the actual processing experiment is carried out, the measured error of the right tooth surface of the ring gear is 9.3 $\mu \mathrm{m}$, and the detection result of the right tooth surface of the ring gear according to the previous processing parameters is $21.1 \mu \mathrm{m}$.

Based on the above analysis results, it can be seen that, although there are many researches on the machining deformation of thin-walled and weak stiffness structural parts, but there are few researches on specific materials in vehicle transmission system, especially for some specific materials (such as $42 \mathrm{CrMo}$ ) used in automobile gearbox ring gear, and there is still a lack of a complete set of process parameter selection principles for the purpose of deformation control to guide the actual production.

Compared with the traditional gear steel $20 \mathrm{CrMnTi}, 42 \mathrm{CrMo}$ steel has the characteristics of high yield strength, good impact resistance, good hardenability, small deformation during quenching and tempering, but low hardness. Due to its good properties, $42 \mathrm{CrMo}$ steel is widely used in automobile gearbox ring gear. However, $42 \mathrm{CrMo}$ has low plasticity, high shear strength and slightly poor thermal conductivity. Therefore, in the process of gear shaping of $42 \mathrm{CrMo}$ ring gear, there are some problems such as large cutting force, high cutting temperature and tool wear[9], which will adversely affect the machined surface roughness and machining accuracy of the parts. Therefore, it is of great significance to study the influence of cutting parameters on the processing deformation and surface roughness of $42 \mathrm{CrMo}$ gear ring in gear shaping process for controlling the processing quality, improving efficiency and reducing production cost of $42 \mathrm{CrMo}$ gear ring.

Therefore, this research takes the gear ring of $42 \mathrm{CrMo}$ steel as the research object. The material of the experimental gear ring is $42 \mathrm{CrMo}$ steel, and its manufacturing process is: forging blank $\rightarrow$ turning $\rightarrow$ quenching and tempering $\rightarrow$ turning $\rightarrow$ internal gear shaper $\rightarrow$ external gear hobbing $\rightarrow$ nitriding heat treatment. After quenching and tempering, the hardness of the workpiece is about $35 \mathrm{hrc}$. This paper 
focuses on the internal gear shaping process. In the second part of this paper, the finite element simulation of chip deformation, cutting force and cutting temperature in the forming process of $42 \mathrm{CrMo}$ ring gear is carried out; in the third part, the actual cutting test of 42CrMo ring gear is introduced, the influence of cutting parameters on forming deformation and surface roughness is discussed, and the research conclusion of the fourth part is given.

\section{Simulation analysis of gear shaping process}

\subsection{The establishment of simulation model}

The gear shaping process of gear ring is a typical discontinuous cutting process. Because the gear shaping cutter not only has its own rotation movement, the reciprocating movement in the axis direction and the radial movement, but also the workpiece continues to rotate, the relative position and movement relationship between them are more complex than the general turning process.On the other hand, the shape of tooth corresponding to each stroke gear shaper cutter is different, and the cross-section shape of each tooth is not the same, resulting in different shapes of new teeth shape.In order to be more consistent with the actual process of gear shaping, it is necessary to establish the cutter tooth model and workpiece model which are consistent with the actual processing in gear ring gear shaping simulation.

Gear shaper cutter can be regarded as a series of single cutter teeth with the same shape rotating around the central axis. When establishing the simulation model of gear shaper machining process, because all the cutter teeth have the same geometry, when modeling the gear shaper cutter, it can be simplified to take a certain gear shaper cutter tooth as the cutter model. According to the drawing of gear shaper cutter matched with the actual workpiece, the model of gear shaper cutter is established in the ProE software. The material of the tool selected in the software is 'coating TiALN'.Then, based on the model of gear shaper cutter, a single gear shaper cutter is cut. And finally, it is imported into the finite element simulation software to complete the establishment of the gear model, whose model is shown in Fig. 2.
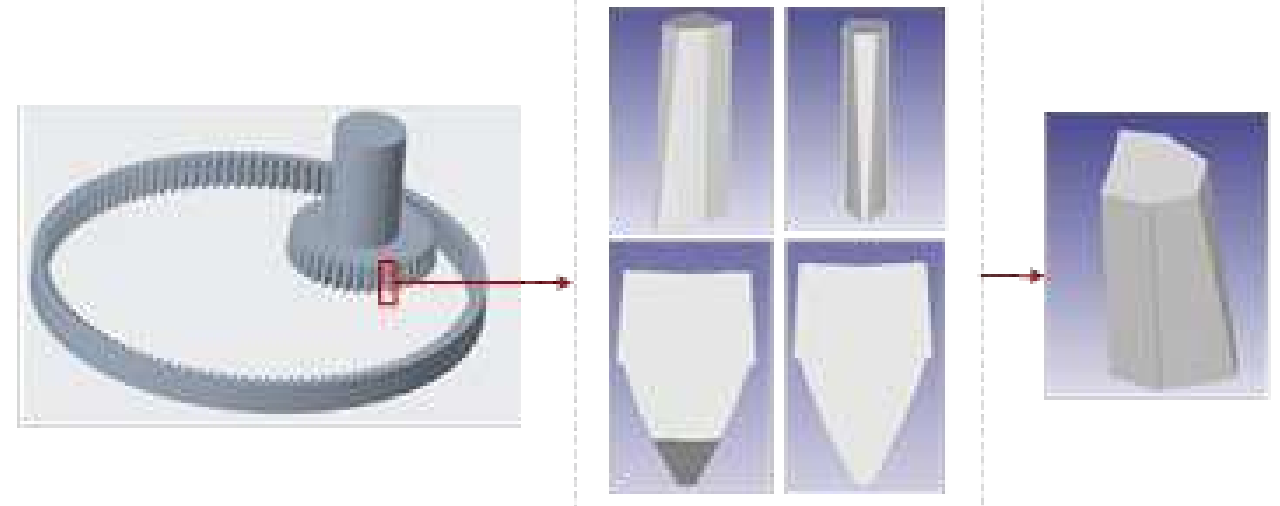

Fig.2 Tooth simulation model of gear shaper cutter

In the process of gear shaping, because of the difference of cutting materials in each stroke, it is very important to establish the tooth slot model of the previous stroke and the current stroke. When the radial cutting depth is $4 \mathrm{~mm}$, the radial feed is $0.02 \mathrm{~mm} / \mathrm{str}$, and the circumferential feed is $0.2 \mathrm{~mm} / \mathrm{str}$, the relationship between the number of strokes and the cutting cross-sectional area is shown in Fig.3. 


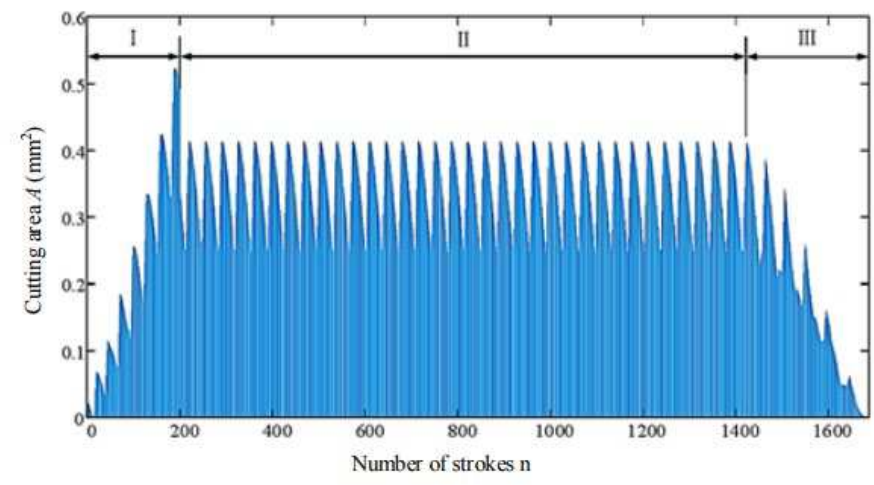

Fig.3 Stroke number and cutting section area

In the first interval, before the radial feed is completed, the center distance between the tool and the workpiece continuously changes, and the cutting cross-sectional area increases in a fluctuating manner.In the third section, after one rotation of the workpiece, the teeth that have not reached the preset machining depth are machined to the set depth, at which time the maximum cutting cross-sectional area continues to decrease. The second section is for tooth machining to reach the set machining depth. The change of the cutting cross-sectional area is more stable, and the corresponding cutting force change rule is also more stable. Therefore, the simulation selects the gear forming process in the second section.

In the ProE software, the cogging model of the workpiece is established according to the workpiece size, the cutter geometry size, the set cutting depth and the circular feed.The relevant expressions are shown in Table 1.

Table 1 Expressions related to cogging modeling

\begin{tabular}{lccc}
\hline \multicolumn{1}{c}{ Content } & Equation & No. & \multicolumn{1}{c}{ Parameter description } \\
\hline $\begin{array}{l}\text { Center distance between } \\
\text { gear shaper and inner ring } \\
\text { gear } O_{1} O_{2}\end{array}$ & $O_{1} O_{2}=R_{1}-R_{2}+a_{p}$ & $(2-1)$ & $\begin{array}{l}R_{1} \text { Is the radius of the tooth top circle of the } \\
\text { workpiece, } R_{2} \text { is the tool radius, } a_{p} \text { is the cutting } \\
\text { depth }\end{array}$ \\
$\begin{array}{l}\text { Rotation angle of } \\
\text { workpiece in each stroke } \omega_{1}\end{array}$ & $\omega_{1}=\left(f_{c} / \pi d_{1}\right) * 360$ & $(2-2)$ & $\begin{array}{l}f_{c} \text { is the circumferential feed rate of each } \\
\text { stroke, } d_{1} \text { is the diameter of the graduation circle } \\
\text { of the workpiece }\end{array}$ \\
$\begin{array}{l}\text { Tool rotation angle per } \\
\text { stroke } \omega_{2}\end{array}$ & $\omega_{2}=\left(f_{c} / \pi d_{2}\right) * 360$ & $(2-3)$ & $d_{2}$ is the pitch circle diameter of the tool \\
\hline
\end{tabular}

The formation process and cutting cross section of the $\mathrm{m}_{\mathrm{th}}$ cogging model are shown in Fig.4.When the center distance is $\mathrm{O}_{1} \mathrm{O}_{2}$, the gear slot shape of the m-1th stroke is shown in the figure. When the tool rotates $\omega_{1}$ and the workpiece rotates $\omega_{2}$, the $m_{t h}$ machining position is reached,and the $\mathrm{m}_{\mathrm{th}}$ gear slot shape is formed after cutting. In ProE software, by performing the Boolean intersection operation on the rotated model, the cutting cross-sectional shape and area of the $\mathrm{m}_{\mathrm{th}}$ machining position can be obtained.

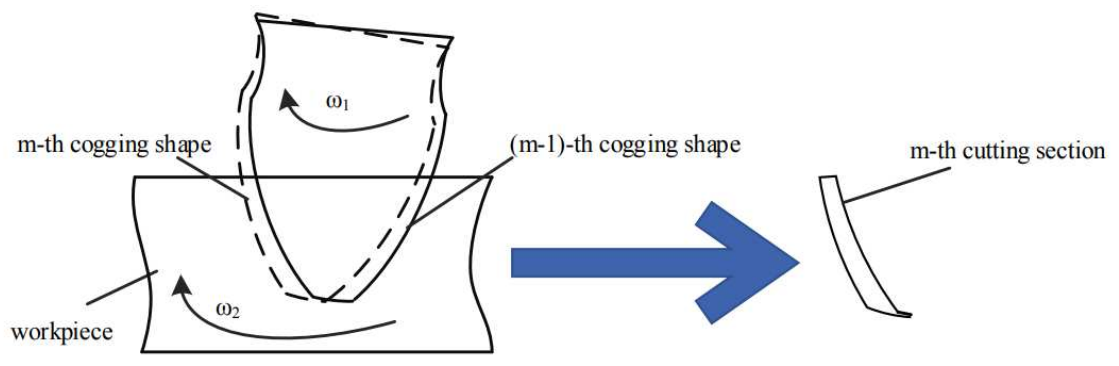

Fig.4 Schematic diagram of cogging and cutting section 
In order to reduce the number of model meshes, when building a solid model, a complete ring gear model is not established, but a certain tooth groove of the ring gear is used as an example, as shown in the following Fig.5. The minimum mesh size of the workpiece grid is $1 / 3$ of the feed rate.

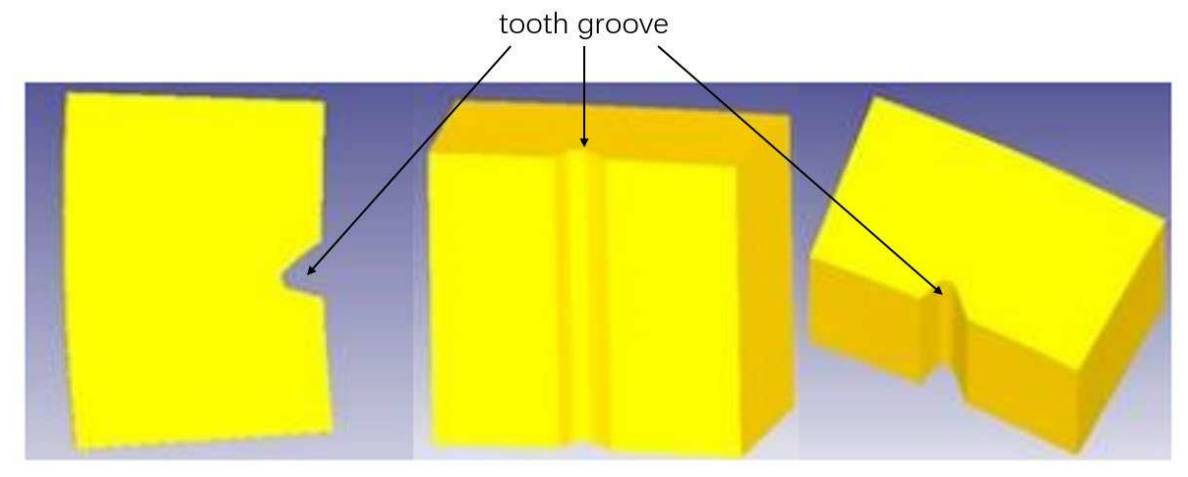

Fig.5 Cogging model

\subsection{Relevant settings of shaper finite element simulation}

The setting of key parameters for the finite element simulation of gear shaping is the basis to ensure accurate and reasonable simulation results. It mainly includes material constitutive model, chip separation and fracture criterion, gear cutter-chip friction model, mesh division. The relevant options are shown in Table 2.

Table 2 Simulation key parameter settings

\begin{tabular}{|c|c|c|}
\hline project & significance & set up \\
\hline $\begin{array}{c}\text { Material } \\
\text { constitutive model }\end{array}$ & $\begin{array}{c}\text { The inherent properties of materials, which represent } \\
\text { the deformation parameters such as strain, } \\
\text { temperature and strain rate, determine the mechanical } \\
\text { behavior of materials }[10] .\end{array}$ & Johnson cook model \\
\hline $\begin{array}{l}\text { Chip separation } \\
\text { and fracture } \\
\text { principle }\end{array}$ & $\begin{array}{l}\text { The appropriate chip separation criterion can ensure } \\
\text { that the chips fall off in a reasonable way during the } \\
\text { simulation process. }\end{array}$ & Cockcroft \& Latham fracture criterion \\
\hline $\begin{array}{l}\text { Knife chip friction } \\
\text { model }\end{array}$ & $\begin{array}{l}\text { Friction model has an important influence on cutting } \\
\text { force, cutting temperature and chip deformation. }\end{array}$ & Zorev's bond slip model[11] \\
\hline Meshing & $\begin{array}{l}\text { Mesh generation has an important influence on the } \\
\text { accuracy of simulation results and the length of } \\
\text { solution time }\end{array}$ & Adaptive mesh generation \\
\hline
\end{tabular}

\section{3 simulation results}

2.3.1Analysis of chip deformation in gear shaping

In the actual production of gear shaper, Zheng pantuo found that the actual chip thickness should be observed in time. When there are very thick or very thin chips, the tool should be polished or the cutting parameters should be adjusted in time to avoid unnecessary wear when the tool enters the rapid wear stage, which can effectively improve the processing efficiency of the product and prolong the service life of the gear shaper tool[11]. Therefore, this study collected and observed the chips produced in the process of gear shaping by visual inspection.

Comparing the chip obtained by finite element simulation with the chip collected by actual gear shaping, it is very similar in shape and deformation law (as shown in Fig.6). 


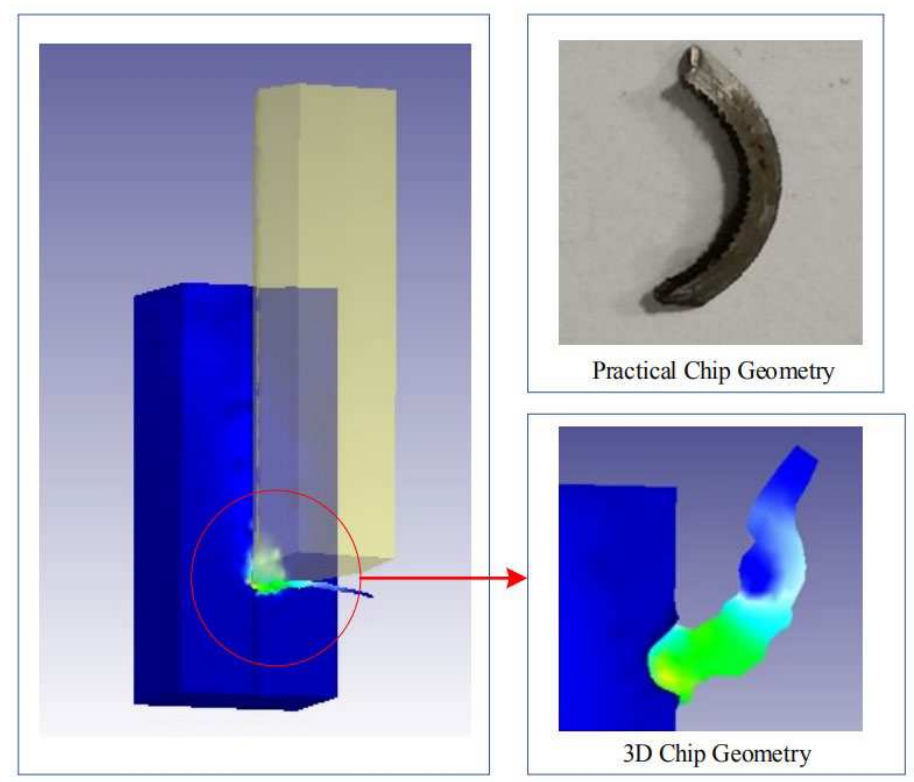

Fig.6 Comparison between simulation chip and actual workshop chip

In the process of $42 \mathrm{CrMo}$ gear ring gear shaping, due to the influence of processing environment, coolant and other factors, compared with the simulation model, the chip shape obtained by actual gear shaping is more diverse and the chip deformation is more complex, as shown in Fig. 7.

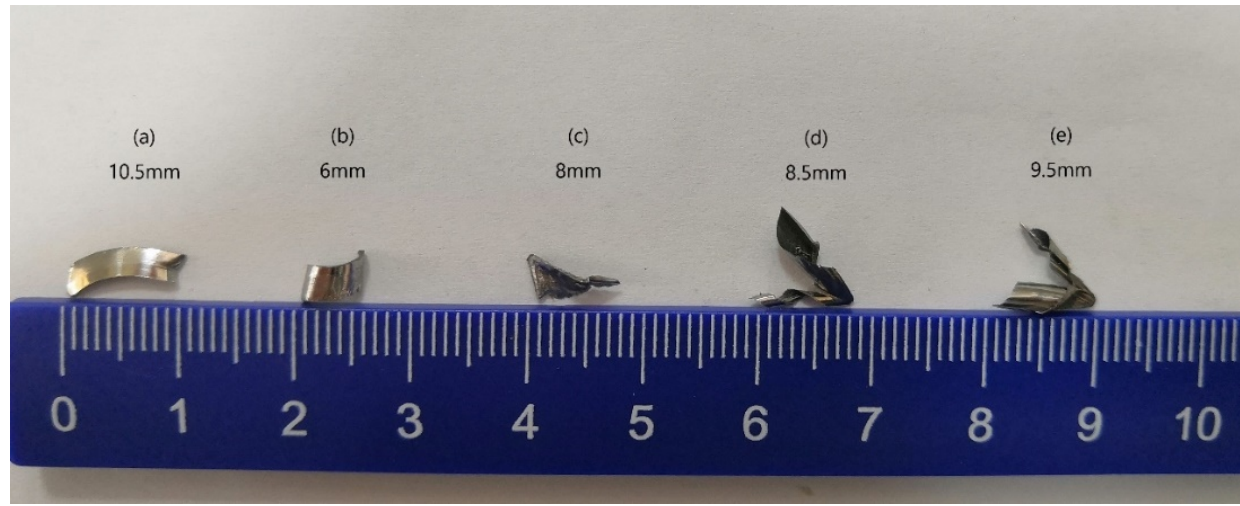

Fig.7 42CrMo gear ring actual gear shaping chip diagram

When the contact area between the gear shaper tool and the workpiece is narrow and the cutting thickness is large, the chip deformation is small and thicker, mostly in an arc shape. This is because the too long chip is broken, which is similar to the simulation result, as shown in Fig. 7(a). When the gear shaper cutter contacts the workpiece too wide and the chip thickness is thin, the chips are bent and the chip surface is large, as shown in Fig. 7(b). When the cutting width is too wide or too narrow, the chips are easy to break and the degree of curl is small. As shown in Fig. 7 (a), (b), (c). When the material to be removed is relatively slender, the chips will completely curl toward the machined surface, as shown in Fig. 7(d) and (e), and the chips are not prone to breakage, mostly band-shaped chips.

Although the stroke speed and feed rate remain constant, the chip shape produced in the process of gear shaping is still diverse.Due to the formation movement, the meshing conditions of the tool and the workpiece change, and the cutting tool will produce chips with different cross-sectional shapes.It is 
not difficult to find from the collected chips, although the shape of the chips is diverse, there are many similar chips.

For a single cutter tooth, during the processing of a single tooth slot, the shape of the tooth slot corresponding to each stroke is different. However, when different teeth are cutting different tooth slots, because the machining process is the same, the cutting shape is similar, so many chips with similar shapes are produced.It reflects that the cutting simulation of a single gear shaping cutter can simulate the gear shaping process of multiple cutters. It also shows that although the gear shaping process is complicated, its chip deformation has certain rules.

\subsubsection{Analysis of cutting force and temperature in gear shaping}

Simulation cutting is carried out under the processing parameters of stroke speed of $200 \mathrm{str} / \mathrm{min}$, circular feed of $2 \mathrm{~mm} / \mathrm{str}$ and cutting depth of $4 \mathrm{~mm}$. The relationship between the main cutting force and time is shown in Fig.8. It can be found from Fig. 8 that the main cutting force rises rapidly firstly, and gradually rises to near the peak as the strain rate strengthens. It is mainly because the main cutting force increases sharply when the tool just cuts into the workpiece. Afterwards, the stable fluctuations, rather than smooth curves, are mainly due to the uneven deformation of the workpiece during the cutting process. Towards the end, the main cutting force quickly decreases, because the amount of the workpiece being cut becomes less and the cutting resistance decreases, and when the cutting movement ends, the main cutting force becomes 0 .

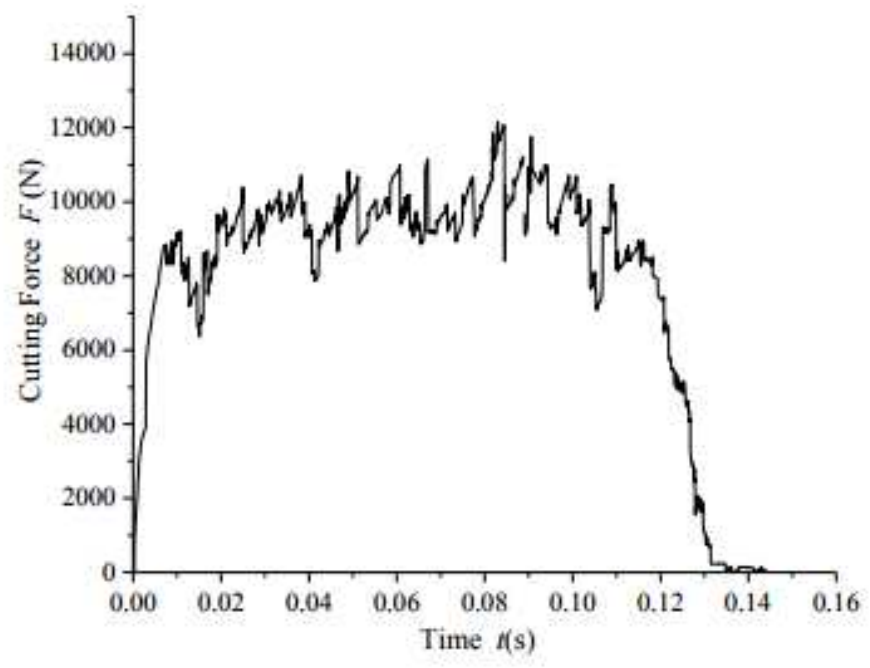

Fig.8 Main cutting force load

The simulation results show that the cutting temperature trend of workpiece and tool is shown in Fig.9. 


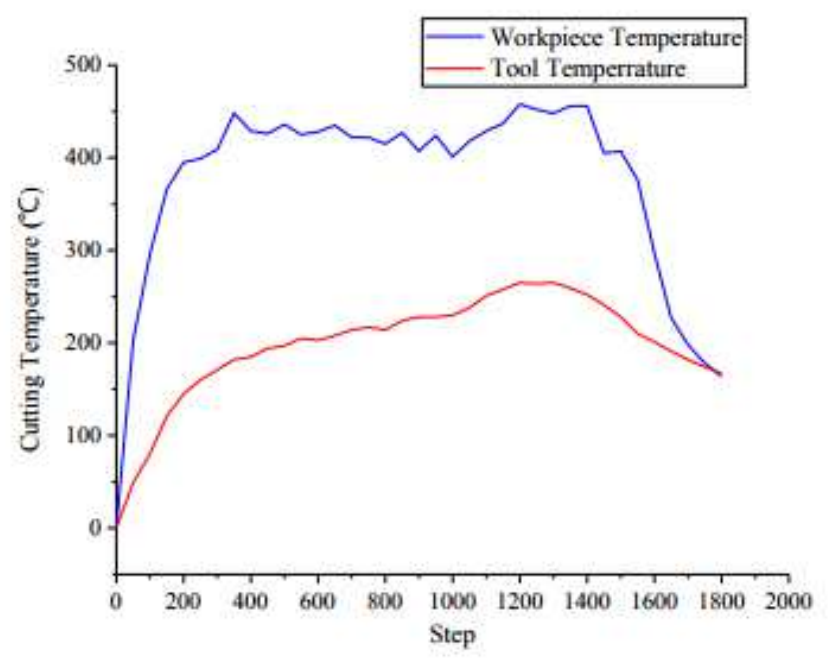

Fig.9 Simulated cutting temperature

From Fig. 9, it can be seen that the temperature of the tool and the workpiece increases rapidly as the tool just cuts into the workpiece at the beginning of cutting. With the progress of cutting, the temperature of both keeps a relatively stable fluctuation. When the tool cuts out the workpiece, the temperature of both decreases rapidly. The maximum temperature of workpiece in the whole cutting process is $466^{\circ} \mathrm{C}$, the maximum temperature of the tool is $267^{\circ} \mathrm{C}$. The temperature of workpiece in cutting is much higher than that of tool, and when the cutting is finished, the decreasing trend of temperature is much higher than that of tool, which also shows that the heat dissipation of tool is not good. According to the literature, the tool wear problem in the process of internal gear shaping is mainly caused by the interference in the process of gear shaping, mainly due to the elimination of the interference[13]. In this study, the simulation results at step 1140 are shown in Fig. 10.
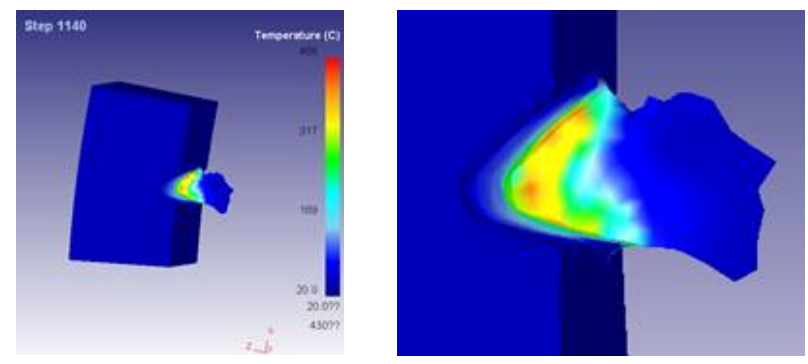

(a) Temperature distribution of workpiece
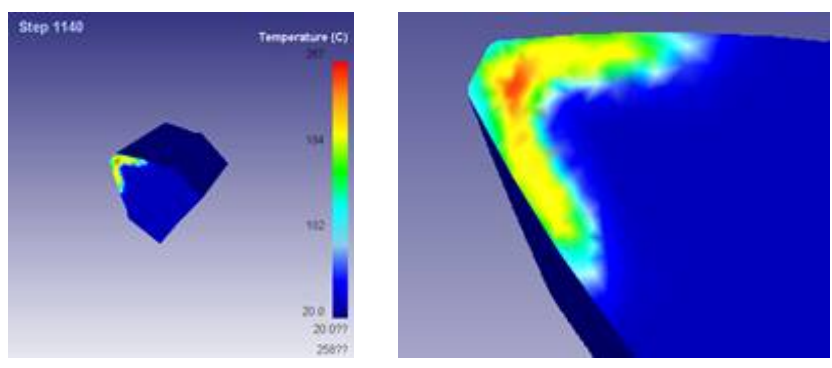

(b) Tool temperature distribution

Fig.10 Temperature distribution of workpiece and tool 
From Fig. 10 (a), it can be seen that the temperature in the plastic deformation area of the workpiece is relatively high during gear shaping cutting, and most of the heat in the workpiece is exported through the chips. It can be seen from Fig. 10 (b) that in the process of gear shaping, the temperature of the tool at the tip is higher, followed by the tool faces on both sides. Based on the simulation analysis, it can be found that the cutting heat is mainly concentrated in the contact part between the ring gear and the tool tip, and the temperature can reach up to $430^{\circ} \mathrm{C}$. When the chips flow out, the friction between the chips and the front face makes the temperature near the cutting edge higher, which is consistent with the phenomenon that the tip of the gear shaper tool turns white when it is used for a long time in actual cutting.

Because of the poor thermal conductivity of the tool, the gear shaper tool tip is easy to wear under high temperature. In the process of gear shaping, the wear of gear shaper cutter has a direct impact on the product processing quality and efficiency. In actual production, the wear value of gear shaper cutter is usually set at $0.1 \sim 0.3 \mathrm{~mm}$, and different values are selected according to the modulus of gear shaper cutter. For example, for small and medium modulus gear shaper cutter, the wear standard of $0.1 \mathrm{~mm}$ is often set. When the number of workpieces processed by the gear shaper cutter reaches the preset wear amount, the gear shaper cutter needs to be polished[13].

\subsubsection{Influence of cutting parameters on cutting force and cutting temperature}

In order to study the influence of gear shaping cutting parameters on cutting force and cutting temperature in the process of gear shaping, the orthogonal cutting simulation experiment with gear shaping cutting parameters as influencing factors and cutting force and cutting temperature as indicators was designed. The average value of the stable cutting stage is used as the simulation test value, and the value when the tool is cut in and out and part of the sudden change value are removed.The difference between test design and simulation junction is shown in Table 3. The range analysis of the test results is shown in Table 4. $\mathrm{T}_{i}$ represents the sum of the main cutting forces of each factor at level $i . \bar{X}_{\iota}$ represents the average value of the main cutting forces at each level at level $i$.And the range is $\bar{X}_{l_{\text {max }}}-\overline{\mathrm{X}}_{l_{\text {min }}}$. The greater the range of the factor, the greater the influence of the factor on the value of the main cutting force index within the test range.

Table 3 Simulation test and results of gear shaping cutting force

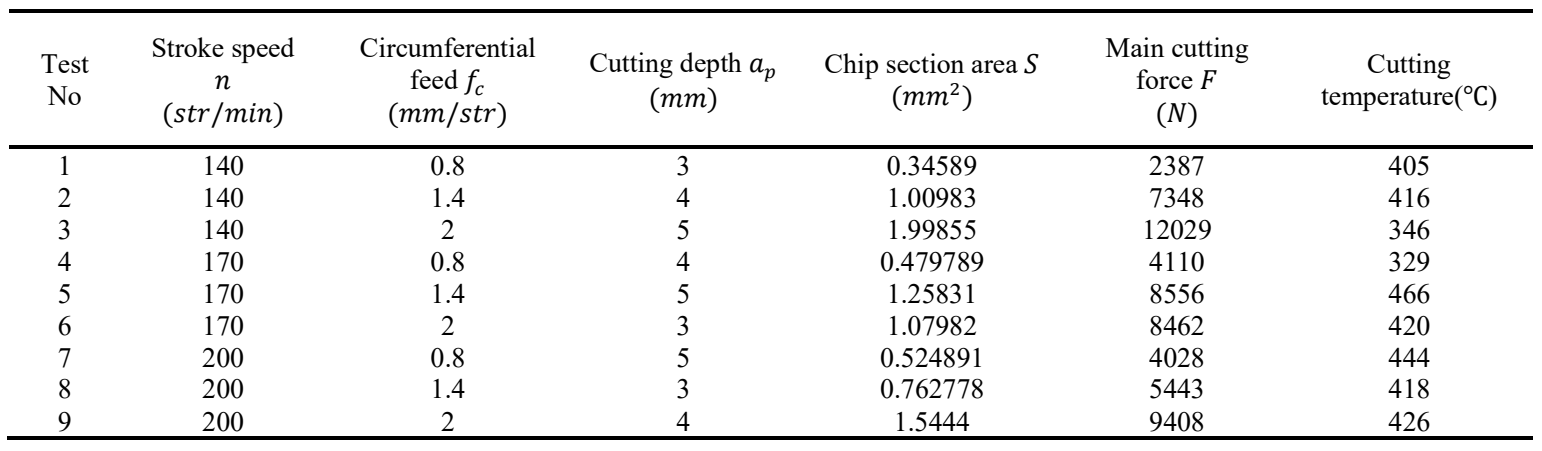


Table 4 Range analysis results

\begin{tabular}{|c|c|c|c|c|}
\hline & \multirow{2}{*}{ level } & \multicolumn{3}{|c|}{ factor } \\
\hline & & $n(\mathrm{str} / \mathrm{min})$ & $f_{c}(\mathrm{~mm} / \mathrm{str})$ & $a_{p}(\mathrm{~mm})$ \\
\hline \multirow{7}{*}{$\begin{array}{l}\text { Main cutting } \\
\text { force } F(N)\end{array}$} & $T_{1}$ & 21764 & 10525 & 16538 \\
\hline & $T_{2}$ & 21128 & 21593 & 20866.00 \\
\hline & $T_{3}$ & 19125 & 29899 & 24613.00 \\
\hline & $\overline{X_{1}}$ & 7254.67 & 3508.33 & 5512.67 \\
\hline & $\overline{X_{2}}$ & 7042.67 & 7197.67 & 6955.33 \\
\hline & $\frac{2}{X_{3}}$ & 6375.00 & 9966.33 & 8204.33 \\
\hline & range & 879.667 & 6458.000 & 2691.667 \\
\hline \multicolumn{2}{|c|}{ Importance ranking } & 3 & 1 & 2 \\
\hline \multirow{7}{*}{$\begin{array}{l}\text { cutting } \\
\text { temperature } \\
T\left({ }^{\circ} \mathrm{C}\right)\end{array}$} & $T_{1}$ & 1167 & 1178 & 1243 \\
\hline & $T_{2}$ & 1215 & 1300 & 1171.00 \\
\hline & $T_{3}$ & 1288 & 1192 & 1256.00 \\
\hline & $\overline{X_{1}}$ & 389.00 & 392.67 & 414.33 \\
\hline & $\overline{X_{2}}$ & 405.00 & 433.33 & 390.33 \\
\hline & $\overline{X_{3}}$ & 429.33 & 397.33 & 418.67 \\
\hline & range & 40.333 & 40.667 & 28.333 \\
\hline \multicolumn{2}{|c|}{ Importance ranking } & 2 & 1 & 3 \\
\hline
\end{tabular}

Through the range analysis of the orthogonal test, it can be found that among the cutting parameters used in the test, the circumferential feed has the most significant effect on the main cutting force of the gear shape, followed by the cutting depth, and the stroke speed has the smallest effect on the main cutting force. The influence of circular feed and stroke speed on cutting temperature is significant and almost equal, while the influence of cutting depth on cutting temperature is small. According to the results of orthogonal test and analysis, the influence of cutting parameters and indicators, main cutting force and cutting temperature is shown in Fig. 11.

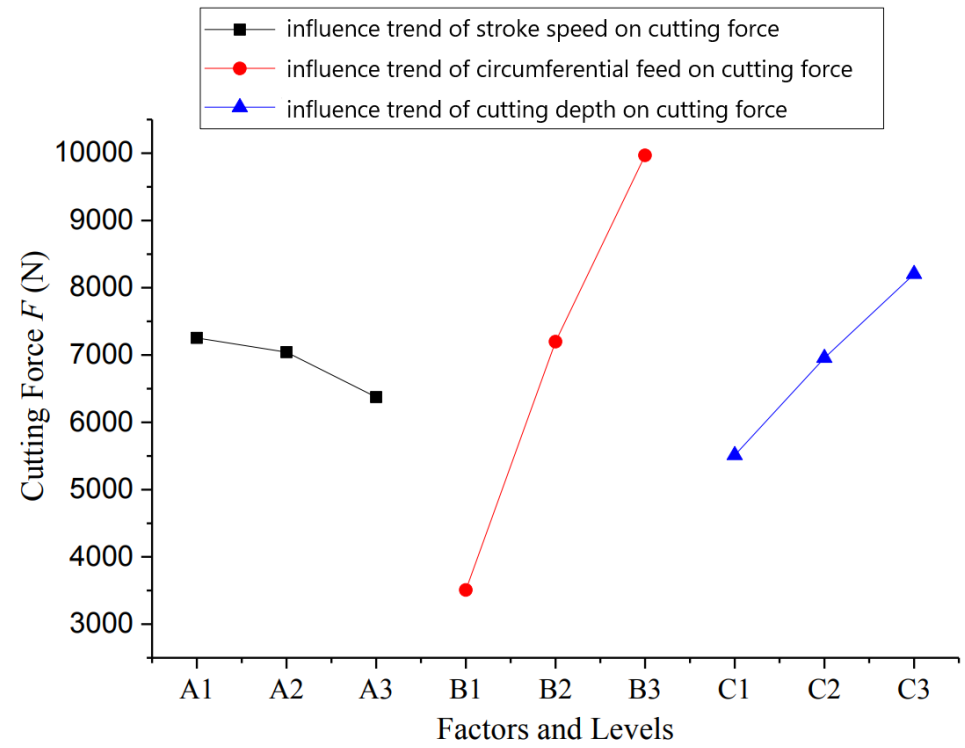

Fig.11 Influence trend of gear shaping cutting parameters on main cutting force

(1) The influence of stroke speed on the main cutting force. As shown in Fig. 11, with the increase of stroke speed, the main cutting force shows a downward trend. Due to the influence of gear shaper and cutter, the stroke speed setting is relatively small $(7.8 \mathrm{~m} / \mathrm{min} \sim 11.2 \mathrm{~m} / \mathrm{min})$. When the cutting speed is small, there will be great friction resistance. With the increase of cutting speed, the cutting temperature 
will increase, the strength and hardness of the material to be cut will decrease, the resistance of cutting deformation will decrease, and the main cutting force will also decrease.

(2) The influence of the circumferential feed on the main cutting force. As shown in Fig. 11, the main cutting force increases with the increase of the circumferential feed. The circumferential feed can be expressed as the arc length of the workpiece rotation after each reciprocating motion of the tool. At the same cutting speed and cutting depth, the larger the arc length of the workpiece rotation, the larger the cutting area of the tool and the greater the cutting force.

(3) The influence of cutting depth on the main cutting force. As shown in Fig. 11, with the increase of cutting depth, the main cutting force shows an increasing trend. Because of the increase of cutting depth, it means that the deeper the tool cuts into the workpiece, the more amount of single cutting is involved in the same circular feed, which results in the increase of cutting force.

(4) The influence of chip area on the main cutting force.In the Proe software, the cutting section area of each experiment is extracted, and the relationship between the chip section area and the main cutting force is drawn. It can be seen from Fig. 12 that at the same stroke speed, the main cutting force increases with the increase of chip cross-section area. Because of the large cross-section area, the more resistance the gear shaper cutter overcomes, the greater the main cutting force is, and the reliability of the simulation results is verified from the side.

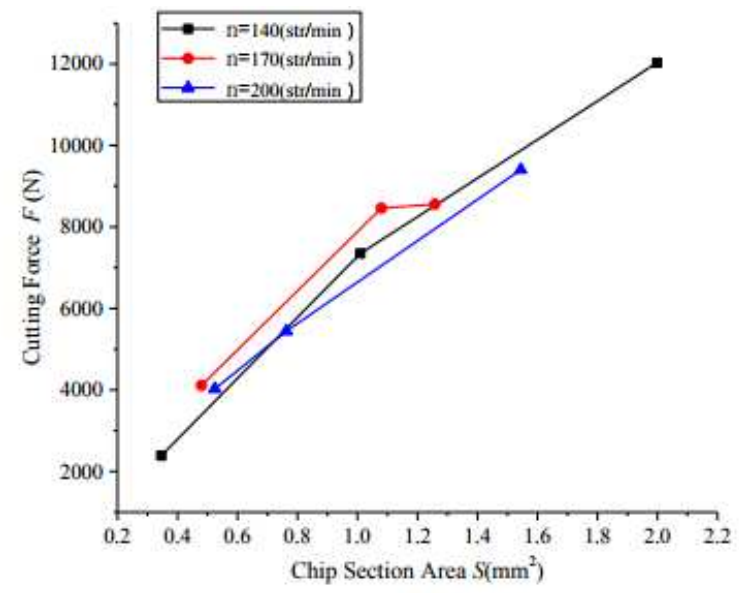

Fig.12 The relationship between chip section area and main cutting force 


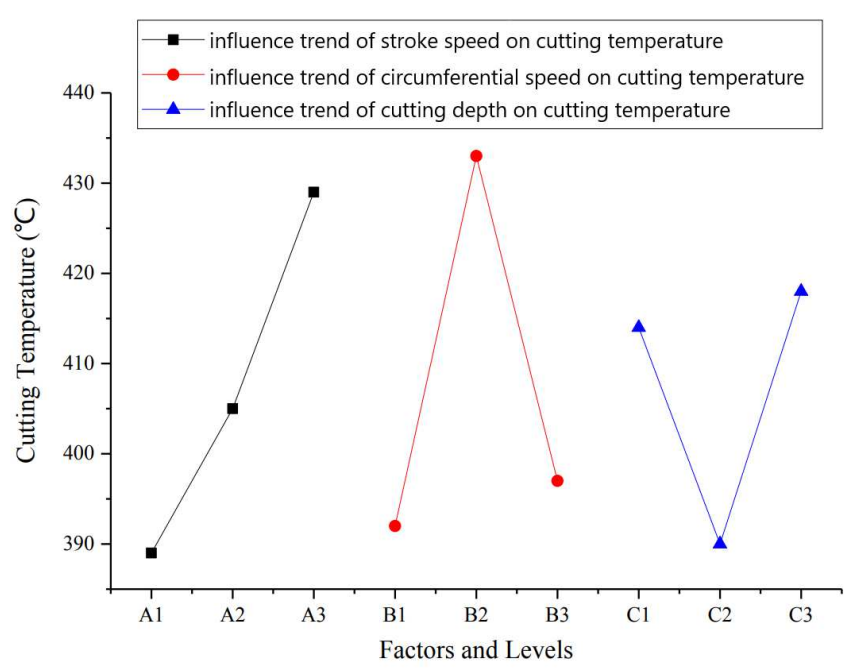

Fig.13 Influence trend of gear shaping cutting parameters on cutting temperature

According to the results of orthogonal test analysis, the influence of each cutting parameter and cutting temperature is shown in Fig.13, and the specific analysis is as follows:

(1) The influence of stroke speed on cutting temperature. With the increase of stroke speed, the cutting temperature shows an increasing trend. The increase of stroke speed, that is, the increase of cutting speed, will increase the cutting heat and the cutting temperature, but the cutting temperature will not increase linearly with the increase of speed, because the increase of cutting speed will accelerate the conduction of cutting heat and affect the cutting temperature.

(2) The influence of circumferential feed on cutting temperature. With the increase of the circular feed, the cutting temperature shows a trend of first rising and then falling. The increase of circumferential feed will increase the cutting thickness, resulting in an increase in the cutting area, which in turn increases the cutting force and the cutting temperature. But on the other hand, when the cutting thickness increases, it will also lead to the increase of the heat taken away by the chip and the decrease of the temperature in the cutting area.

(3) The influence of cutting depth on cutting temperature. With the increase of cutting depth, the cutting temperature shows a trend of first decreasing and then increasing. The increase of cutting depth will increase the amount of cutting and the heat taken away by chips. But too large cutting depth will increase the cutting force and the cutting temperature.

\section{Experimental research}

In order to study the deformation of gear ring in the actual process of gear shaping, the relevant cutting experiments of gear ring deformation with gear shaping cutting parameters (stroke speed, circumferential feed, radial feed and cutting depth) as factors and gear ring deformation (roundness difference before and after machining) as indicators were designed and implemented.

\subsection{Experimental Conditions}

Details of the experiment mainly include test gear ring, cutter, machine tool, testing equipment, the design parameters of the ring gear are shown in Table 5. 
Table 5 Gear design parameters

\begin{tabular}{cc}
\hline Item & Value \\
\hline Materials & $42 \mathrm{CrMo}$ \\
Modulus & 2.25 \\
Number of teeth & 95 \\
Pressure angle & $25^{\circ}$ \\
Base circle diameter & 193.723 \\
Diameter of index circle & 213.75 \\
Starting diameter of involute & Max 210.9 \\
Tooth root circle diameter & $221_{0}^{+0.30}$ \\
Tooth width & 20 \\
\hline
\end{tabular}

The experimental cutter used the bowl-shaped straight gear cutter produced by Hanjiang Tool Company, its detailed parameters are shown in Table 6.

Table 6 Experimental cutter information

\begin{tabular}{cc}
\hline Item & Value \\
\hline Material & $\mathrm{S} 390$ \\
Hardness & $66-67 \mathrm{HRC}$ \\
Coating & TiAIN \\
Coating thickness & $2 \mu \mathrm{m}$ \\
Normal phase modulus & 2.25 \\
Pressure angle & $25^{\circ}$ \\
Front angle & $7^{\circ}$ \\
Back angle & $5^{\circ}$ \\
Base circle helix angle & $2^{\circ} 34^{\prime}$ \\
Number of teeth & 56 \\
Chemical composition & $\mathrm{C}<0.2 \% ; \mathrm{Si}<0.4 \% ; \mathrm{Mn}<1.4 \% ; \mathrm{P}<0.025 \% ; \mathrm{S}<0.015 \%$ \\
\hline
\end{tabular}

The machine-tool is Yichang Changjiang Machine Technology CNC gear shaper yk5150h, its detailed parameters are shown in Table 7.

Table 7 Machine-tool information

\begin{tabular}{cc}
\hline item & value \\
\hline name & Yichang Changji Technology CNC Gear Shaper YK5150H \\
model & YK 5150H \\
Maximum machining internal tooth diameter & $600 \mathrm{~mm}$ \\
Maximum processing modulus & 10 \\
Maximum machining tooth width & $140 \mathrm{~mm}$ \\
Maximum stroke speed & $400 \mathrm{str} / \mathrm{min}$ \\
Total power & $22.5 \mathrm{KW}$ \\
\hline
\end{tabular}

Roundness measuring equipment is Italian COORD3 (Ares Series) CMM, its detailed parameters are shown in Table 8.

Table 8 Roundness measuring equipment information

\begin{tabular}{cc}
\hline Item & Value \\
\hline Model & Compact bridge type coordinate measuring machine ARES \\
positioning accuracy & $0.001 \mathrm{~mm}$ \\
Scope of application & $700 * 650 * 500 \mathrm{~mm}$ \\
Measuring stroke & $\mathrm{X}: 700 \mathrm{~mm} ; \mathrm{Y}: 650 \mathrm{~mm} ; \mathrm{Z}: 500 \mathrm{~mm}$ \\
measurement accuracy & ISO MEPP $=3+3.5 \mathrm{~L} / 1000 \mu \mathrm{m}$ \\
Three-dimensional velocity & $<=517 \mathrm{~mm} / \mathrm{s}$ \\
\hline
\end{tabular}

\subsection{Experimental design method}

\subsubsection{Data collection equipment installation}

The force acting on the workpiece and the tool during gear shaping is the relationship between the acting force and the reaction force. Therefore, the cutting force on the workpiece can be decomposed into the cutting force in the $\mathrm{Z}$-axis direction, the cutting force in the $\mathrm{X}$-axis direction and the $\mathrm{Y}$-axis direction, as shown in Fig. 14. 


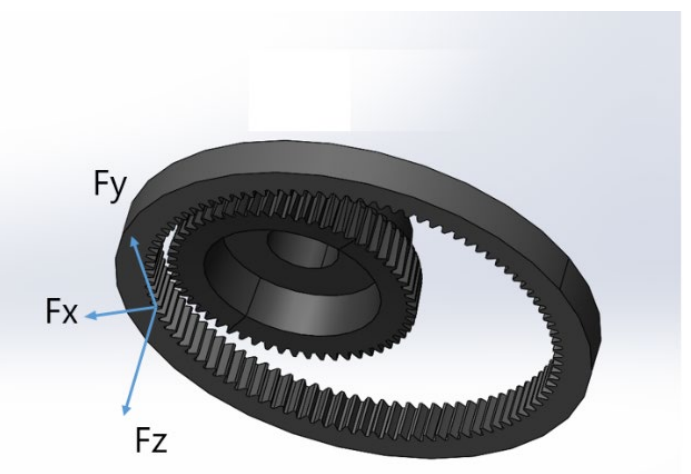

Fig.14 Force decomposition during gear shaping

In order to monitor the change of the cutting force in the z-axis direction and the radial cutting force in the X-axis direction. Install pressure sensors on the lower end surface and outer circle of the ring gear. The sensor is shown in Figure 15. The red film pressure sensor is used to sense the change of the main cutting force Fz, and the yellow film pressure sensor is used to sense the change of the radial cutting force Fx. Figure 15 (a) and (b) are the placement positions of the membrane pressure sensor when the gear is not installed. Figure 15 (c) is a schematic diagram of the relative position of the sensor and the ring gear. As shown in Figure 15(d), the gear shaping is performed after the pressure sensor is installed.

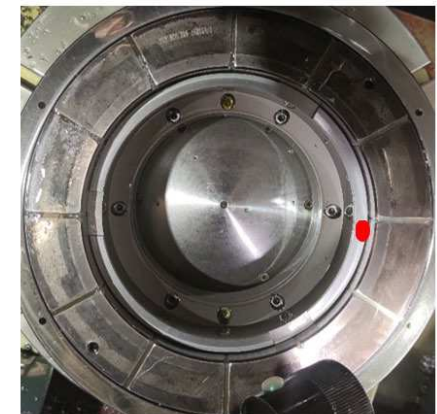

(a)

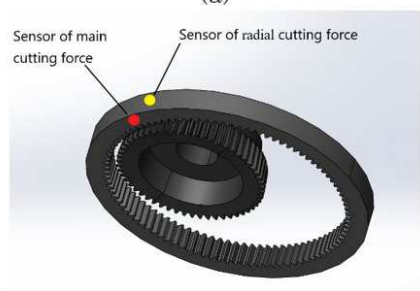

(c)

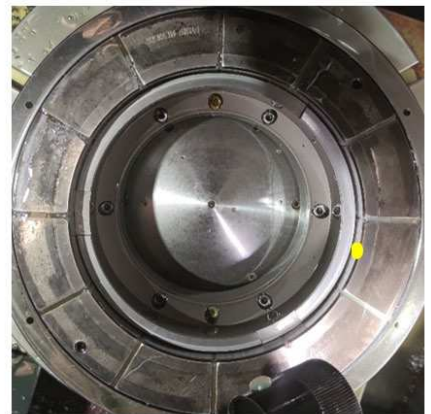

(b)

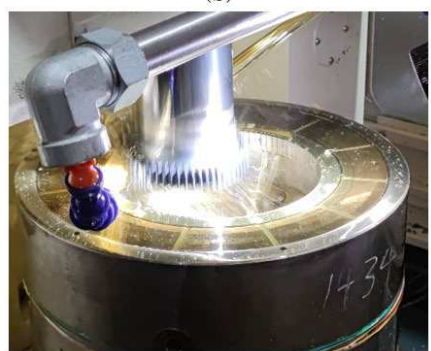

(d)

Fig. 15 Relative position of membrane pressure sensor

\subsubsection{Experimental parameters}

In the gear shaping process, there are four variables (stroke speed, circumferential feed, radial feed, and cutting depth) in one cycle, and some of the variables have a large span. In order to reduce the number of tests and costs, orthogonal tests are used. In the test, the roundness difference before and after processing is used to indicate the deformation. Before and after processing, the ring gear is cleaned and 
dried, and the roundness of the outer circle of the ring gear is measured with a three-coordinate instrument, and the difference in the roundness measurement is used as the deformation the amount. Combining the actual industrial production process, set the machining and cutting parameters, and discuss the influence of each cutting parameter on the deformation of the ring gear. The gear ring is processed under the cooling of L-HM 46 anti-wear hydraulic oil.The designed orthogonal test scheme is shown in Table 9.

Table 9 42CrMo gear ring gear shaping uniform design test table

\begin{tabular}{ccccc}
\hline Test & \multicolumn{4}{c}{ Test parameters } \\
\cline { 2 - 5 } No. & Stroke speed $n(\mathrm{str} / \mathrm{min})$ & Circumferential feed $f_{c}(\mathrm{~mm} / \mathrm{str})$ & Cutting depth $a_{p}(\mathrm{~mm})$ & Radial feed $f_{r}(\mathrm{~mm} / \mathrm{str})$ \\
\hline 1 & 140 & 0.8 & 3 & 0.0015 \\
2 & 140 & 1.4 & 4 & 0.002 \\
3 & 140 & 2 & 5 & 0.0025 \\
4 & 170 & 2 & 3 & 0.002 \\
5 & 170 & 0.8 & 5 & 0.0025 \\
6 & 170 & 1.4 & 3 & 0.0015 \\
7 & 200 & 1.4 & 4 & 0.0025 \\
8 & 200 & 2 & 5 & 0.0015 \\
9 & 200 & 0.8 & 5 & 0.002 \\
\hline
\end{tabular}

\subsection{Experimental results and analysis}

\subsubsection{Results and analysis of main cutting force}

The clamping force of the clamping device is received when not processing, the value displayed at this time is the initial value, which is recorded as $F_{0}$. The main movement of the gear shaper cutter is up and down reciprocating linear movement, including the downward cutting stroke and the upward return empty stroke are the main movements. When the gear shaper moves downward, the indication of the membrane pressure sensor is larger than the initial value, and the indication at this time is recorded as $F_{\text {down }}$. Take the indication of downward movement minus the initial value as the index $F$ to measure the magnitude of the main cutting force, as shown in Eq. 3-1.

$$
F=F_{\text {down }}-F_{0}
$$

Analyze and process the collected main cutting force induction signals, and the results are shown in Table 10.

Table 10 Experimental results and analysis of main cutting force

\begin{tabular}{|c|c|c|c|c|c|}
\hline \multirow[t]{2}{*}{ Test No. } & \multicolumn{4}{|c|}{ Test parameters } & \multirow{2}{*}{$\begin{array}{c}\text { Test result } \\
\text { tangential } \\
\text { compression force }\end{array}$} \\
\hline & $\begin{array}{c}\text { Stroke speed } \\
n(\text { str } / \text { min })\end{array}$ & $\begin{array}{c}\text { Circumferential feed } \\
f_{c}(\mathrm{~mm} / \mathrm{str})\end{array}$ & $\begin{array}{c}\text { Cutting depth } \\
a_{p}(\mathrm{~mm})\end{array}$ & $\begin{array}{l}\text { Radial feed } \\
f_{r}(\mathrm{~mm} / \mathrm{str})\end{array}$ & \\
\hline 1 & 140 & 0.8 & 3 & 0.0015 & 386 \\
\hline 2 & 140 & 1.4 & 4 & 0.002 & 418 \\
\hline 3 & 140 & 2 & 5 & 0.0025 & 447 \\
\hline 4 & 170 & 2 & 3 & 0.002 & 413 \\
\hline 5 & 170 & 0.8 & 4 & 0.0025 & 397 \\
\hline 6 & 170 & 1.4 & 5 & 0.0015 & 425 \\
\hline 7 & 200 & 1.4 & 3 & 0.0025 & 392 \\
\hline 8 & 200 & 2 & 4 & 0.0015 & 413 \\
\hline 9 & 200 & 0.8 & 5 & 0.002 & 401 \\
\hline I & 1251 & 1184 & 1191 & 1224 & \\
\hline II & 1235 & 1235 & 1228 & 1232 & \\
\hline III & 1206 & 1273 & 1273 & 1236 & \\
\hline$\overline{\mathrm{I}}$ & 417 & 394.6667 & 397 & 408 & \\
\hline$\overline{\mathrm{II}}$ & 411.6667 & 411.6667 & 409.3333 & 410.6667 & \\
\hline$\overline{\mathrm{III}}$ & 402 & 424.3333 & 424.3333 & 412 & \\
\hline Range & 15 & 29.6667 & 27.3333 & 4 & \\
\hline Importance ranking & 3 & 1 & 2 & 4 & \\
\hline
\end{tabular}



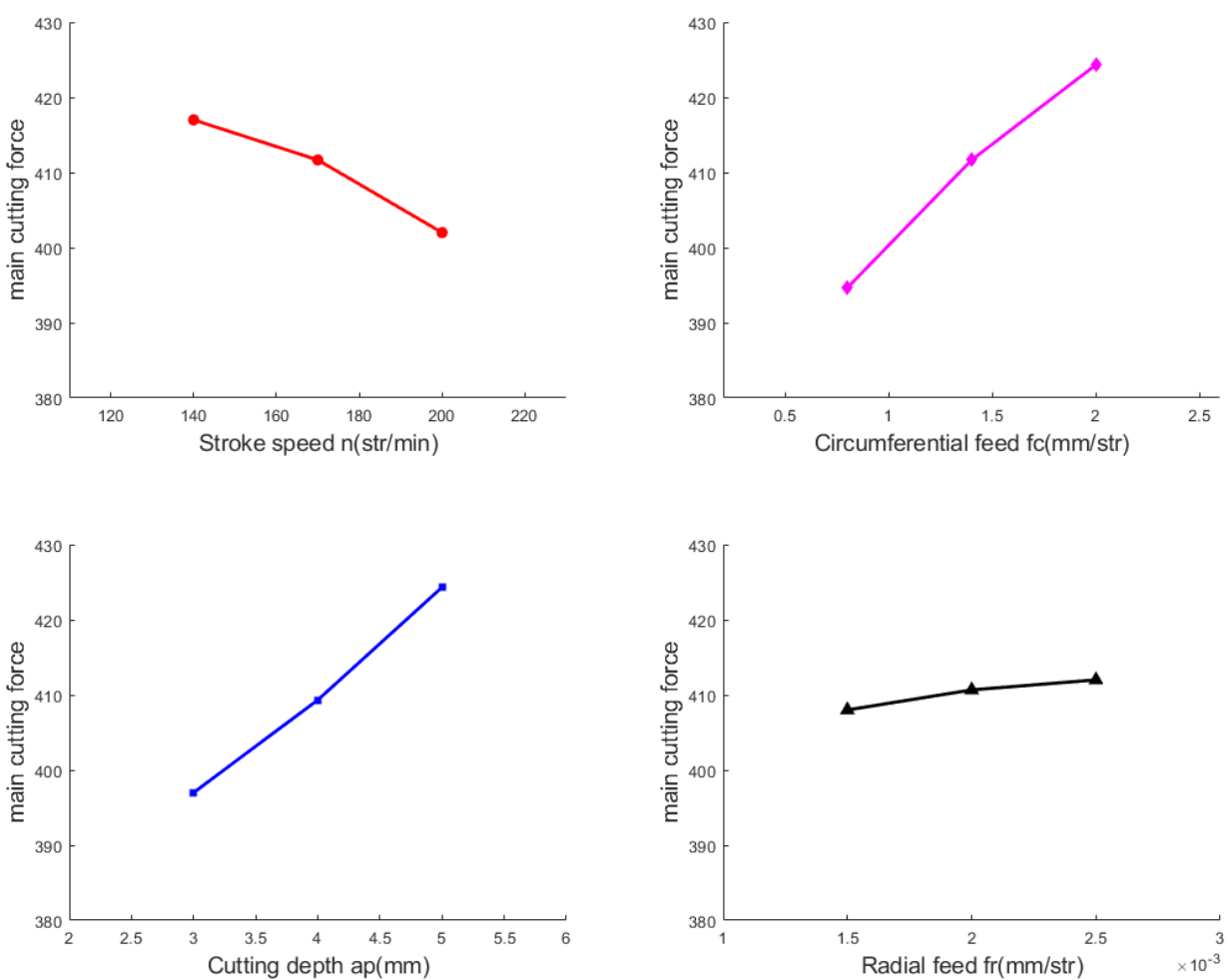

Fig. 16 The influence trend of parameters on the main cutting force

From Table 10 and Fig.16, we can see that the influence of cutting parameters on the main cutting force in descending order is circumferential feed, depth of cut, stroke speed and radial feed.The cutting depth and circumferential feed have a very obvious influence on the main cutting force, and the main cutting force increases in proportion to the increase in the cutting depth and circumferential feed. On the premise that other cutting parameters remain unchanged, the cutting depth increases, the cross-sectional area of the shear layer cut by the tool will increase, the cutting resistance during cutting will increase, and the corresponding main cutting force will also increase. The increase in the circumferential feed will also increase the cross-sectional area of the shear area, so the main cutting force will increase accordingly. When cutting at a lower cutting speed, there is greater frictional resistance. When the cutting speed increases to a certain value, the cutting temperature rises, and the strength and hardness of the material to be cut will decrease, so the cutting resistance in the shearing zone will decrease. The main cutting force is reduced. Han Jun et al. used a bowl-shaped gear shaper to design and experimentally process a $20 \mathrm{Cr} 2 \mathrm{Ni} 4 \mathrm{~A}$ gear ring, and obtained the relationship between cutting force and processing parameters. The cutting speed is between $20-32 \mathrm{~m} / \mathrm{min}$, and the cutting force decreases as the cutting speed increases. The amount of back attack is between $1.0-3.0 \mathrm{~mm}$, and the cutting force increases with the increase of the amount of back attack[8]. This is similar to the result of our experiment. Comparing Fig. 11 and Fig. 16, the results obtained by finite element simulation are basically the same as those obtained by experiments. Stroke speed, circumferential feed and cutting depth have the same order of influence on the main cutting force. And their influence trends on the main cutting force are very close. The feasibility 
of using finite element simulation to analyze the influence trend of machining parameters on the main cutting force is proved.

3.3.2 Results and analysis of radial cutting force

The clamping force of the clamping device is received when not processing, the value displayed at this time is the initial value, which is recorded as $F_{r 0}$. When gear shaping is carried out to the position where the thin film pressure sensor is placed, the indicator of the thin film pressure sensor will increase under the influence of the radial cutting force. The indicator at this time is recorded as $F_{\max }$, and the increased value is the radial cutting force The measurement value of is $\mathrm{F}_{\mathrm{r}}$, and the calculation method is Eq. 3-2.

$$
F_{r}=F_{\text {max }}-F_{r 0}
$$

Analyze and process the collected radial cutting force induction signals, and the results are shown in Table 11.

Table 11 Orthogonal Test Analysis of Radial Cutting Force

\begin{tabular}{|c|c|c|c|c|c|}
\hline \multirow{2}{*}{ Test No. } & \multicolumn{4}{|c|}{ Test parameters } & \multirow{2}{*}{$\begin{array}{c}\text { Test result } \\
\text { radial compressive } \\
\text { force }\end{array}$} \\
\hline & $\begin{array}{c}\text { Stroke speed } \\
n(\text { str } / \text { min })\end{array}$ & $\begin{array}{c}\text { Circumferential feed } \\
f_{c}(\mathrm{~mm} / \mathrm{str})\end{array}$ & $\begin{array}{c}\text { Cutting depth } \\
a_{p}(\mathrm{~mm})\end{array}$ & $\begin{array}{l}\text { Radial feed } \\
f_{r}(\mathrm{~mm} / \mathrm{str})\end{array}$ & \\
\hline 1 & 140 & 0.8 & 3 & 0.0015 & 89 \\
\hline 2 & 140 & 1.4 & 4 & 0.002 & 106 \\
\hline 3 & 140 & 2 & 5 & 0.0025 & 118 \\
\hline 4 & 170 & 2 & 3 & 0.002 & 97 \\
\hline 5 & 170 & 0.8 & 4 & 0.0025 & 121 \\
\hline 6 & 170 & 1.4 & 5 & 0.0015 & 103 \\
\hline 7 & 200 & 1.4 & 3 & 0.0025 & 97 \\
\hline 8 & 200 & 2 & 4 & 0.0015 & 95 \\
\hline 9 & 200 & 0.8 & 5 & 0.002 & 114 \\
\hline I & 313 & 324 & 283 & 287 & \\
\hline II & 321 & 306 & 322 & 317 & \\
\hline III & 306 & 310 & 335 & 336 & \\
\hline$\overline{\mathrm{I}}$ & 104.3333 & 108 & 94.3333 & 95.6667 & \\
\hline$\overline{\text { II }}$ & 107 & 102 & 107.3333 & 105.6667 & \\
\hline$\overline{\mathrm{III}}$ & 102 & 103.3333 & 111.6667 & 112 & \\
\hline Range & 5 & 6 & 17.3333 & 16.3333 & \\
\hline Importance ranking & 4 & 3 & 1 & 2 & \\
\hline
\end{tabular}



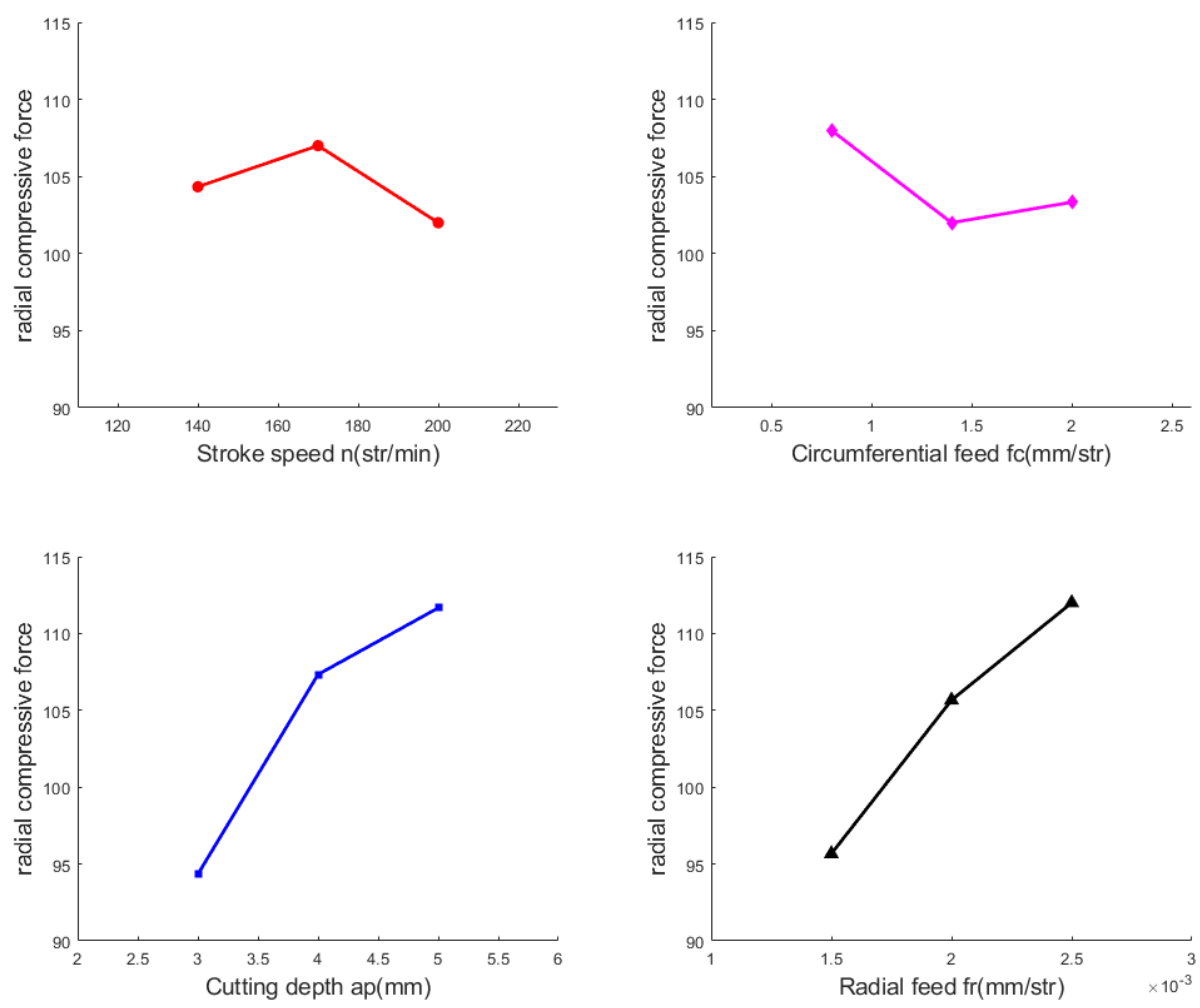

Fig.17 The influence trend of cutting parameters on radial cutting force

From table 11 and Fig.17, we can see that the order of the influence of cutting parameters on the radial force from large to small is cutting depth, radial feed, circumferential feed, stroke speed. Among them, the cutting depth and radial feed have a very obvious influence on the radial cutting force. The radial cutting force increases proportionally as the depth of cut increases, and increases proportionally as the radial feed increases.

\subsubsection{Measurement and analysis of ring gear deformation}

Roundness refers to the condition that the circle on the part is kept equidistant from its center, also called the degree of rounding. It can be expressed as the difference between the radii of two concentric circles that contain the actual contour of the same cross section and have the smallest radius difference[14]. It is the limit to the actual circle. An indicator of the variation of the ideal circle, the tolerance zone is the area between two concentric circles with the tolerance value $t$ as the radius difference, and the actual motion trajectory of the tool tip point is an arbitrary curve in this area, as shown in Fig. 18 (a). 


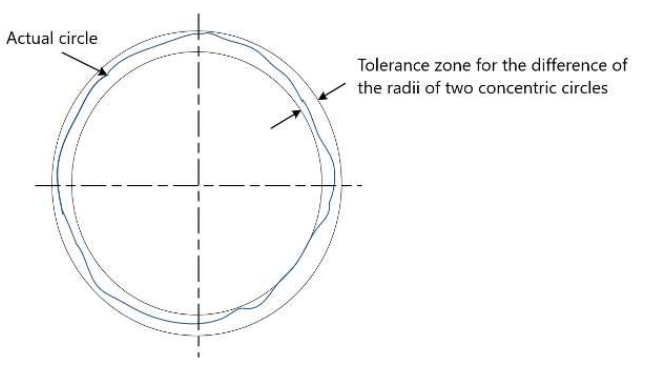

(a) Diagram of roundness

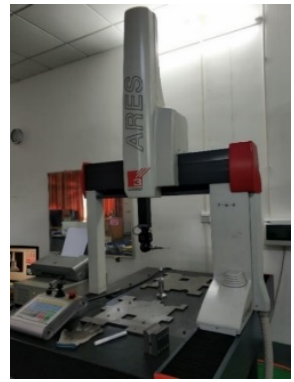

(b) COORD3 (Ares Series) CMM

Fig.18 Roundness and its measurement

In this study, Italian COORD3 (Ares Series) CMM was used to measure the roundness of the gear ring before and after machining, as shown in Fig.18 (b). The measurement results of roundness difference are shown in Table 12, and the influence trend of various parameters on the deformation of ring gear is obtained through analysis, as shown in Fig.19.

Table 12 Orthogonal analysis table of gear ring deformation

\begin{tabular}{|c|c|c|c|c|c|}
\hline \multirow[b]{2}{*}{ Test No. } & \multicolumn{4}{|c|}{ Test parameters } & \multirow{2}{*}{$\begin{array}{c}\text { Test result } \\
\text { Roundness difference } \\
R(\mu \mathrm{m})\end{array}$} \\
\hline & $\begin{array}{c}\text { Stroke speed } \\
n(\mathrm{str} / \mathrm{min})\end{array}$ & $\begin{array}{l}\text { Circumferential } \\
\text { feed } f_{c}(\mathrm{~mm} / \mathrm{str})\end{array}$ & $\begin{array}{c}\text { Cutting depth } \\
a_{p}(m m)\end{array}$ & $\begin{array}{l}\text { Radial feed } \\
f_{r}(\mathrm{~mm} / \mathrm{str})\end{array}$ & \\
\hline 1 & 140 & 0.8 & 3 & 0.0015 & 15.9 \\
\hline 2 & 140 & 1.4 & 4 & 0.002 & -5.1 \\
\hline 3 & 140 & 2 & 5 & 0.0025 & -20 \\
\hline 4 & 170 & 2 & 3 & 0.002 & -22.3 \\
\hline 5 & 170 & 0.8 & 4 & 0.0025 & -6.2 \\
\hline 6 & 170 & 1.4 & 5 & 0.0015 & -6.8 \\
\hline 7 & 200 & 1.4 & 3 & 0.0025 & -35.4 \\
\hline 8 & 200 & 2 & 4 & 0.0015 & -1.6 \\
\hline 9 & 200 & 0.8 & 5 & 0.002 & -6.1 \\
\hline I & -9.2 & 3.6 & -41.8 & 7.5 & \\
\hline II & -35.3 & -47.3 & -12.9 & -33.5 & \\
\hline III & -43.1 & -43.9 & -32.9 & -61.6 & \\
\hline$\overline{\mathrm{I}}$ & -3.06667 & 1.2 & -13.9333 & 2.5 & \\
\hline$\overline{\mathrm{II}}$ & -11.7667 & -15.7667 & -4.3 & -11.1667 & \\
\hline$\overline{\mathrm{III}}$ & -14.3667 & -14.6333 & -10.9667 & -20.5333 & \\
\hline Range & 11.3 & 16.9667 & 9.6333 & 23.0333 & \\
\hline Importance ranking & 3 & 2 & 4 & 1 & \\
\hline
\end{tabular}

It can be seen from the test results that when the roundness error difference before and after processing is positive compared with the original roundness error, the tolerance zone representing the difference between the radii of the two concentric circles becomes larger, that is, the deformation is more serious. When the difference is negative, the tolerance zone of the difference between the radii of the two concentric circles becomes smaller, indicating that the situation is improved compared with the original deformation. It can be seen from the test results that different cutting parameters will cause different degrees of deformation of the ring teeth. 

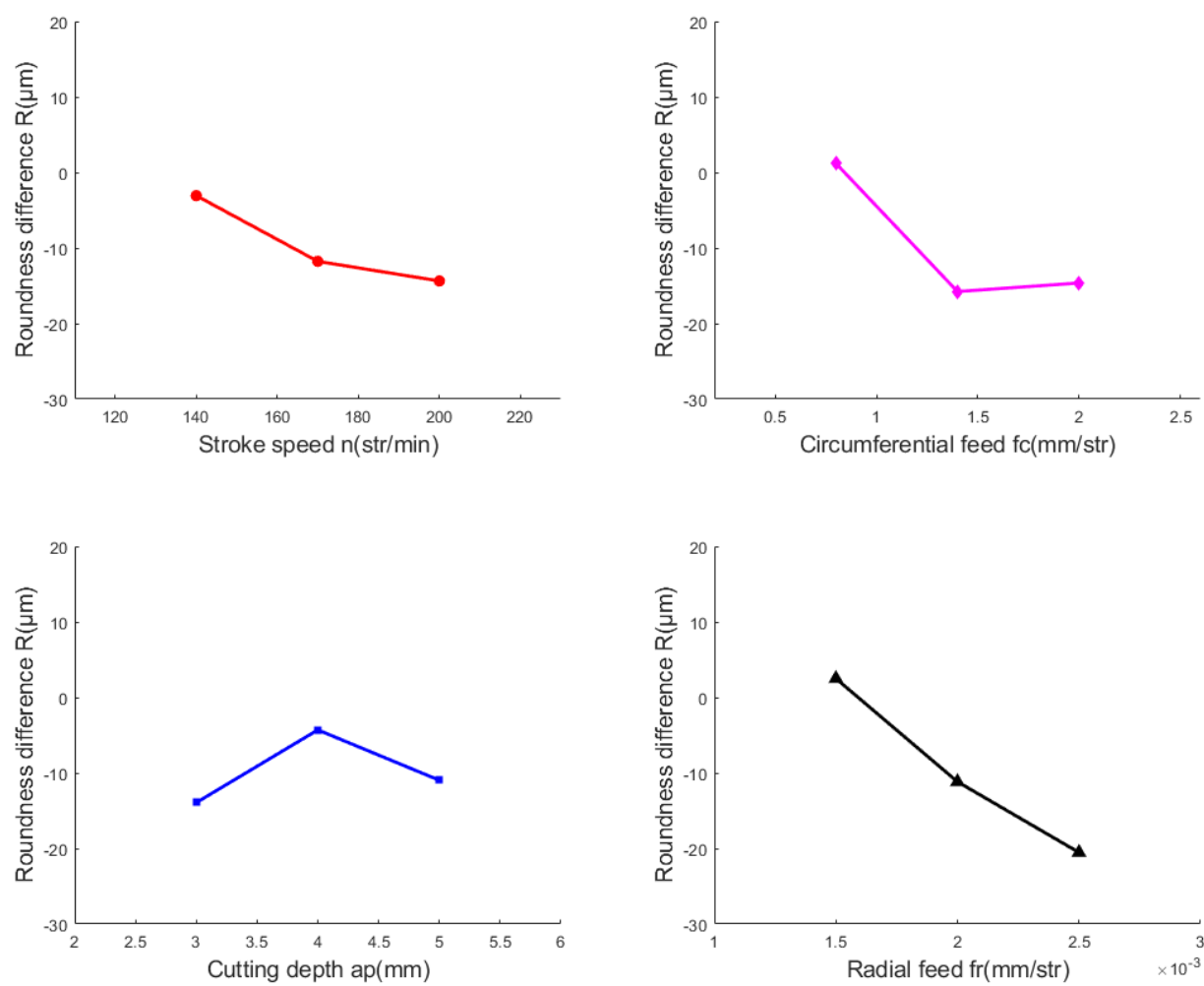

Fig.19 The influence trend of parameters on ring gear deformation

From the results in Table 12 and Fig. 19, it can be seen that the radial feed has the greatest impact on the deformation of the ring gear. When the value of the radial feed increases, the deformation of the ring gear decreases linearly, and the impact is very significant. According to the simulation results in section 2 , in the range of cutting parameters, the cutting force decreases with the increase of stroke speed, and the cutting temperature increases with the increase of stroke speed. But at the same time, the increase of cutting temperature will reduce the friction coefficient and the cutting force[11].

\subsection{Establishment of deformation model of gear ring}

In order to further analyze the relationship between gear ring deformation and cutting parameters, a uniform design test was carried out on the basis of orthogonal experiments. According to the obtained ring gear deformation data, the prediction model of the ring gear deformation was fitted, which can be used to control the deformation of ring gear in its machining process.

In order to improve the uniform dispersion of experimental parameters, the established model is more accurate. Combine the actual production process of the factory with the parameter selection of the orthogonal experiment, and set the processing parameters of the uniform experiment. And use the Italian COORD3 (Ares series) to measure the roundness of the ring gear. The scheme and results of the uniform experiment are shown in Table 13.

Table 13 42CrMo gear ring gear shaping uniform design test table

\begin{tabular}{cccccc}
\hline \multirow{2}{*}{$\begin{array}{l}\text { Test } \\
\text { No }\end{array}$} & \multicolumn{4}{c}{ Test parameters } & Test result \\
\cline { 2 - 6 } & $\begin{array}{c}\text { Stroke speed } \\
(\mathrm{str} / \mathrm{min})\end{array}$ & $\begin{array}{c}\text { Circumferential feed } \\
f_{c}(\mathrm{~mm} / \mathrm{str})\end{array}$ & $\begin{array}{c}\text { Cutting depth } \\
a_{p}(\mathrm{~mm})\end{array}$ & $\begin{array}{c}\text { Radial feed } \\
f_{r}(\mathrm{~mm} / \mathrm{str})\end{array}$ & Roundness difference $R(\mu m)$ \\
\hline 1 & 140 & 0.8 & 6 & 0.004 & -17.8 \\
\hline
\end{tabular}




\begin{tabular}{|c|c|c|c|c|c|}
\hline 2 & 150 & 0.8 & 5 & 0.006 & 1.8 \\
\hline 3 & 160 & 2 & 4 & 0.004 & -4.7 \\
\hline 4 & 170 & 2 & 3 & 0.006 & 7.1 \\
\hline 5 & 180 & 0.8 & 6 & 0.003 & 19.5 \\
\hline 6 & 190 & 0.8 & 5 & 0.005 & 5.2 \\
\hline 7 & 200 & 2 & 4 & 0.003 & -49.7 \\
\hline 8 & 210 & 2 & 3 & 0.005 & -61.3 \\
\hline
\end{tabular}

Stepwise regression analysis was used to establish the regression model of cutting parameters and ring gear deformation. Stepwise regression analysis is a kind of regression analysis. When the selected variable becomes no longer significant after the introduction of new variable, it will be eliminated. When the excluded variable becomes significant after the introduction of new variable, it will be included in the equation again. The quadratic regression equation established by stepwise regression analysis is as Eq. (3-3).

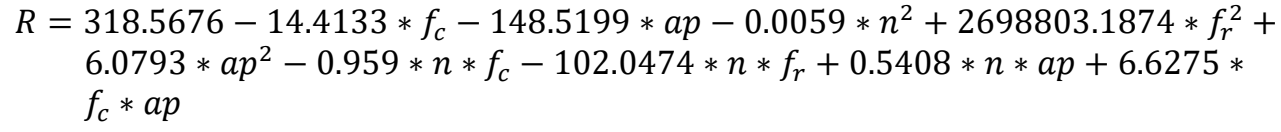

Significance test is usually needed for the established regression equation. In this experiment, the $\mathrm{F}=4.5432>F_{0.05}(9,7)=3.68$, so the regression effect is significant. Determination factor $R^{2}$ is an index to evaluate the linear relationship between variables of regression model. The closer the value is to 1 , the better the fit of the regression equation. Calculate $R^{2}$ according to Eq. (3-4).Decision coefficient obtained in the paper $R^{2}=0.854$, indicating that the dependent variable is very related to the independent variable, and the fitting results are shown in Fig.20.From the fitting results, it can be seen that the predicted value of the model is very close to the measured value, which indicates that the model can predict the machining deformation of gear ring gear shaping.

$$
R^{2}=\frac{S S R}{S S T}=\frac{\sum_{i=1}^{n}\left(\hat{y}_{i}-\bar{y}\right)^{2}}{\sum_{i=1}^{n}\left(y_{i}-\bar{y}\right)^{2}}
$$

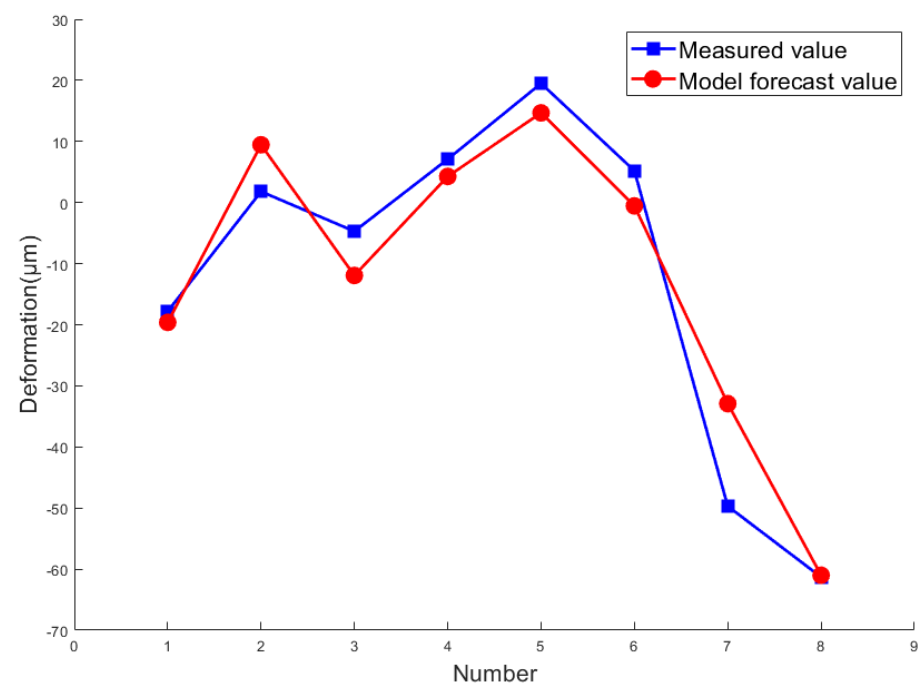

Fig.20 Fitting results of deformation model

In actual machining, the cutting parameters can be adjusted according to the roundness error of the original workpiece to reduce ring tooth deformation. Taking the large roundness error of the original workpiece as an example, the cutting parameters can be selected according to the influence 
trend of the cutting parameters on the deformation of the ring gear in Fig.20. Then calculate the corresponding gear ring deformation according to Eq. (3-3). If the calculated deformation is still greater than the processing requirements, continue to adjust the parameters to reduce the deformation.

\section{Conclusions}

In order to ensure the quality and improve the efficiency of gear shaping, the finite element simulation and practical test are carried out to study the influence of gear shaping cutting parameters on the deformation of gear ring. The main conclusions are as follows:

(1) Among the cutting parameters used in 42CrMo gear shaper cutting simulation test, the circumferential feed has the greatest influence on the main cutting force. The main cutting force increases with the increase of the circumferential feed. But for cutting temperature, the influence of circumferential feed and stroke speed is more significant, while the influence of cutting depth is less.

(2) Through orthogonal experiments, the influence of cutting parameters on the deformation of the ring gear is analyzed. The radial feed has the greatest influence on the deformation of the ring gear, and as the radial feed increases, the deformation of the ring gear decreases. The deformation of the ring gear shows a trend of first decreasing and then increasing with the increase of the circumferential feed. The deformation of the ring gear decreases as the stroke speed increases. The deformation of the ring gear first increases and then decreases with the increase of cutting depth.

(3) The influence of the main cutting parameters on the deformation of the ring gear, from large to small, are in order: radial feed, circumferential feed, stroke speed, cutting depth.

Therefore, in the actual machining, the cutting parameters can be adjusted according to the deformation law of the workpiece during the gear shaping process to achieve the purpose of controlling the deformation of the gear ring. 


\section{Declarations}

\section{-Ethical Approval}

Our research mainly focuses on metal cutting, which does not involve ethical issues.

\section{-Consent to Participate}

All authors consent to participate the submission of this manuscript.

\section{-Consent to Publish}

This manuscript is approved by all authors for publication in IJAMT.

-Authors Contributions

The first author is responsible for planning the whole content of the manuscript, designing and improving the test scheme, the second author is responsible for the analysis of the test and test data, the third author is responsible for the literature analysis and theoretical analysis, and the fourth author is responsible for the simulation analysis.

-Funding

This manuscript is not supported by funding.

-Competing Interests

We declare that we do not have any commercial or associative interest that represents a conflict of interest in connection with the work submitted.

-Availability of data and materials

Relevant data and materials are not included in the manuscript.

\section{Reference}

[1]. Liu ZN, Wang HL, Li HW, Liu XQ. (2018) Research on manufacturing technology of high hardness thin-walled ring gear [J]. Mechanical design and manufacturing, 08: 116-118.

[2]. Liu XJ. (2008)Cutting force model analysis and experimental research of thin-walled parts processing [D]. Tutor: Chen WF. Nanjing University of Aeronautics and Astronautics.

[3]. Cao BR. (2016) Parameter optimization of multi-step turning deformation of parts [D]. Tutor: Fan HL. Beijing Institute of Technology.

[4]. Pang L. (2015) Thermal mechanical coupling simulation analysis and verification of ring gear with weak rigidity [D]. Tutor: Zuo JH, Beijing University of technology.

[5]. Wang J, (2019) Research on Accuracy Improvement of Tooth Shape in Thin Wall Helical Ring[D]. Tutor: Han J, Inner Mongolia University of science and technology.

[6]. García NV, Gonzalo O, Quintana I, Pirling T. (2011) Residual stresses and structural changes generated at different steps of the manufacturing of gears: Effect of banded.

[7]. Kang Q.(2015)Research on the influence of residual stress on the surface of gear ring based on cutting tool wear[D]. Tutor: $\mathrm{Lu}$ JP, Beijing Institute of Technology.

[8]. Han J, Wang J, Duan RX, Zhang L. (2020) Research on the Influence Law of Technological Parameters on the Cut-ting Force of the Gear Ring Gearing Shaping. Machine Tool \&Hydraulics, DOI: 10.3969 / j. issn. 1001 - 3881. 2020. 17. 026.

[9]. Chang HJ. (2018) Research on tool wear and milling parameter optimization in milling 42CrMo die steel [D]. Yanshan University.

[10]. Huang ZG, Ke YL, Wang LT. (2003) Study on Related Techniques for the Finite Element Method Simulation in Metal Cutting [J]. China Mechanical Engineering, 14 (10): 846-849

[11]. Zorev, N. N. (1963). Inter-relationship between shear processes occurring along tool face and shear plane in metal cutting. International research in production engineering, 49, 143-152.

[12]. Zheng PT, (2020) Calculation of chip thickness and selection of cutting parameters for internal gear shaper, Metalworking: cold working, 3:53-56.

[13]. Zheng PT, (2019) Brief Analysis of Interference and Friction of Internal Gear Shaping Process with Fewer Teeth, Tool technology, DOI: 10.3969/j.issn.1000-7008.2019.12.008.

[14]. Liu YY, Guo JK, Li BT, Hong J,Liu ZG. (2019). Error sensitivity analysis and tolerance design of precision machine tools[J]. Journal of Mechanical Engineering (17), 145-152. 


\section{Figures}
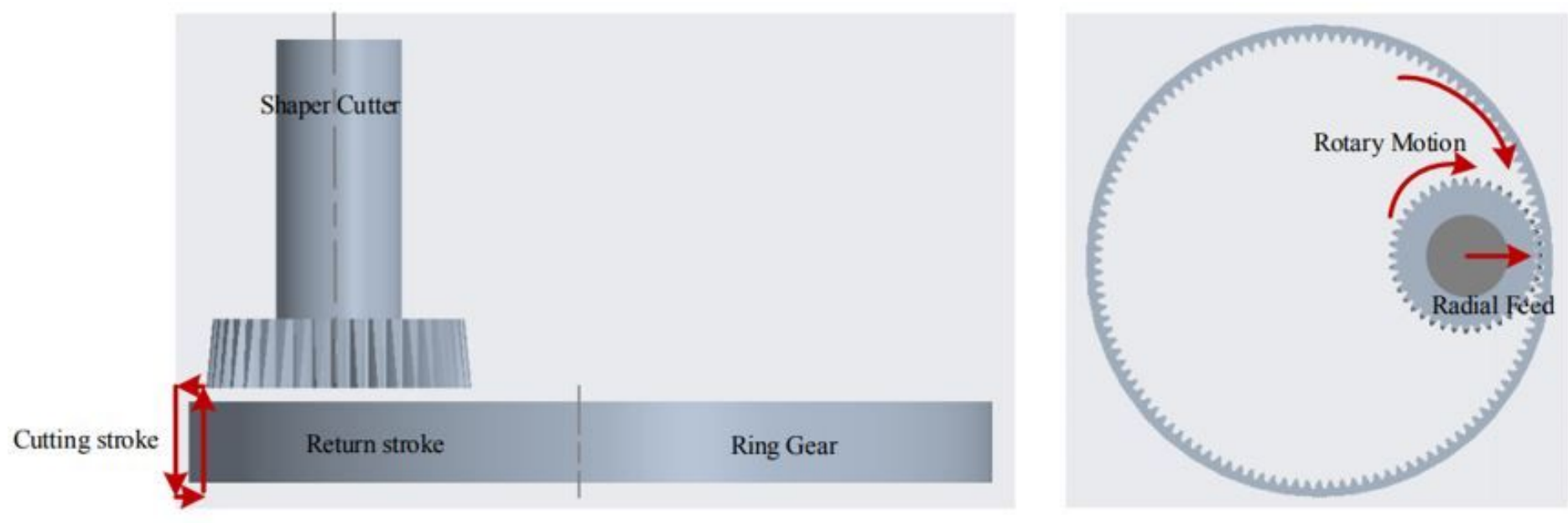

Figure 1

Schematic diagram of gear ring gear shaping
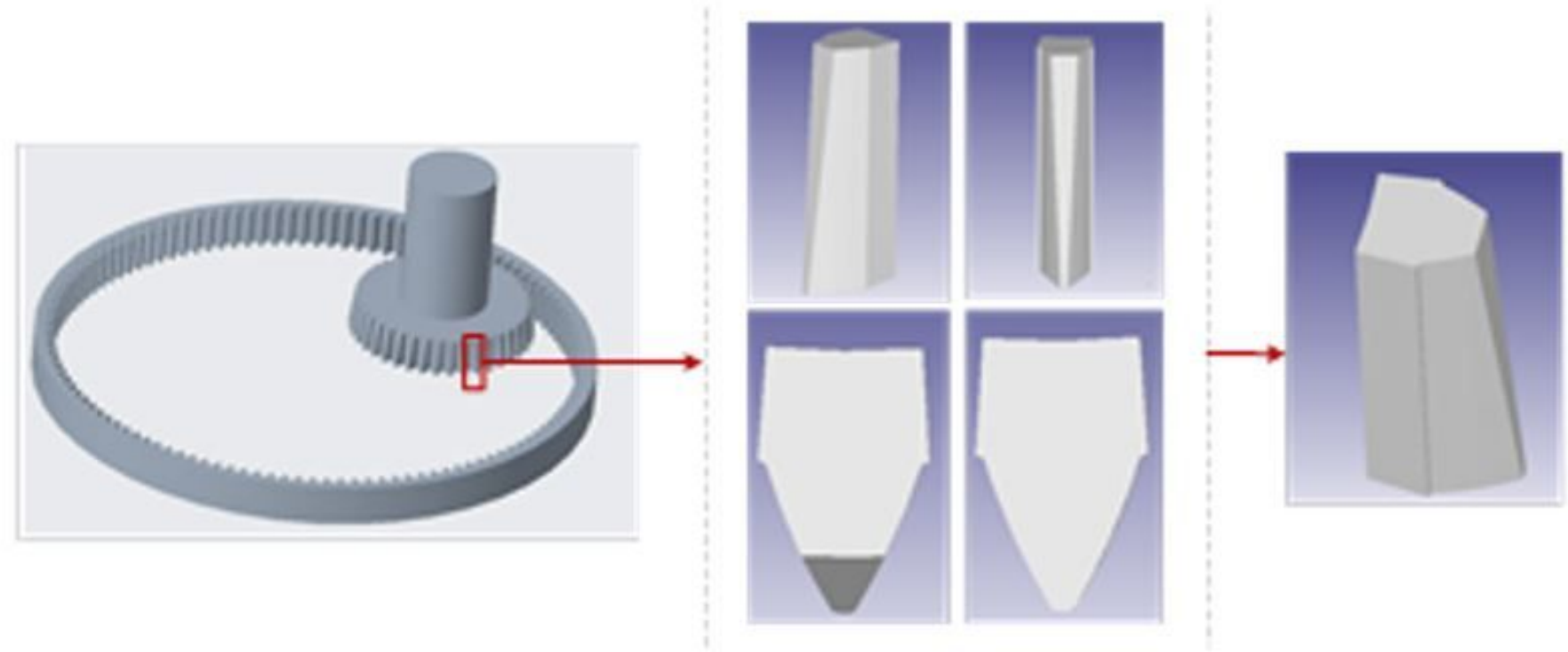

Figure 2

Tooth simulation model of gear shaper cutter 


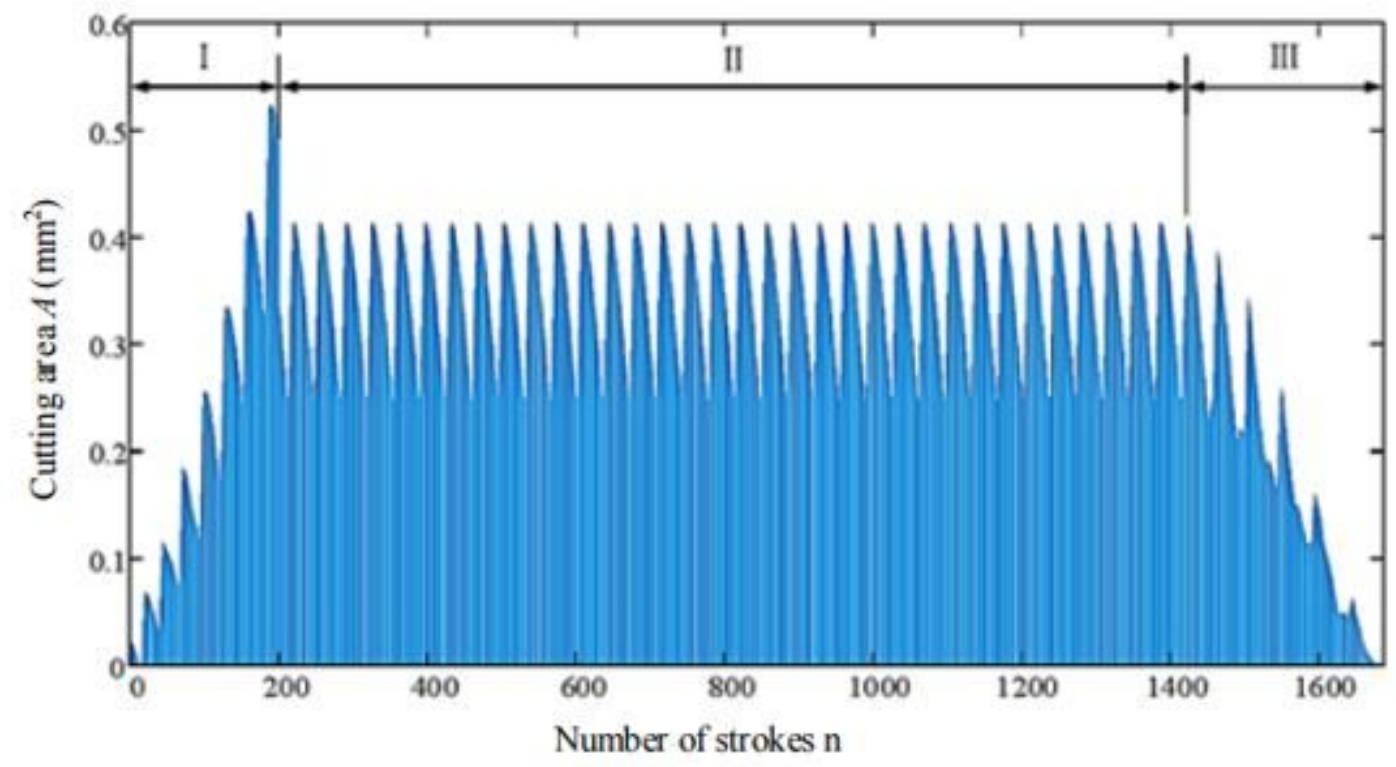

Figure 3

Stroke number and cutting section area

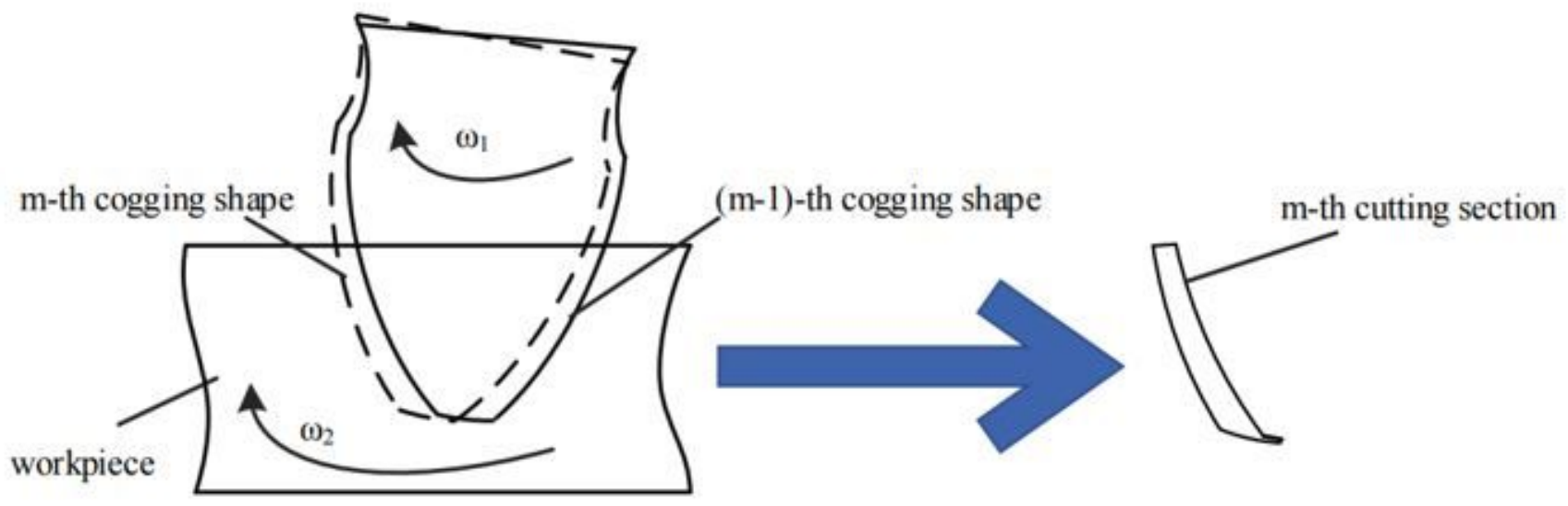

Figure 4

Schematic diagram of cogging and cutting section 


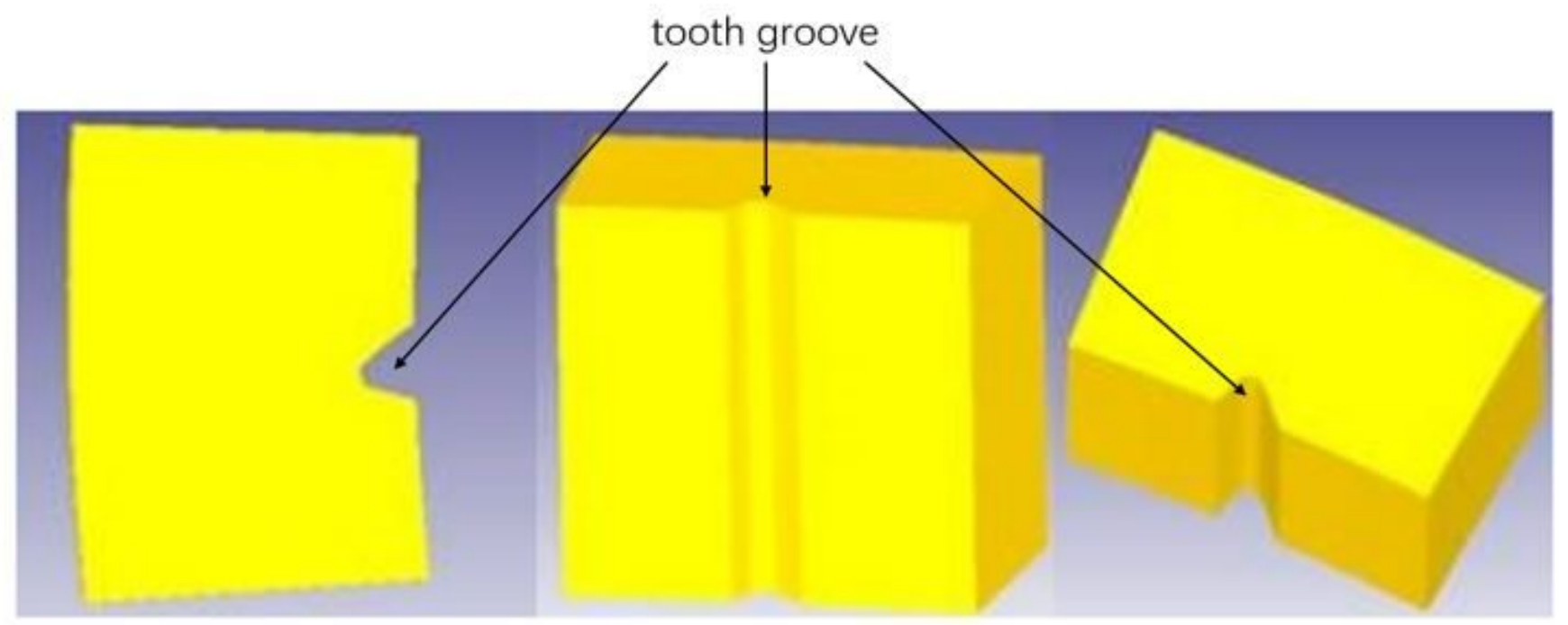

Figure 5

Cogging model

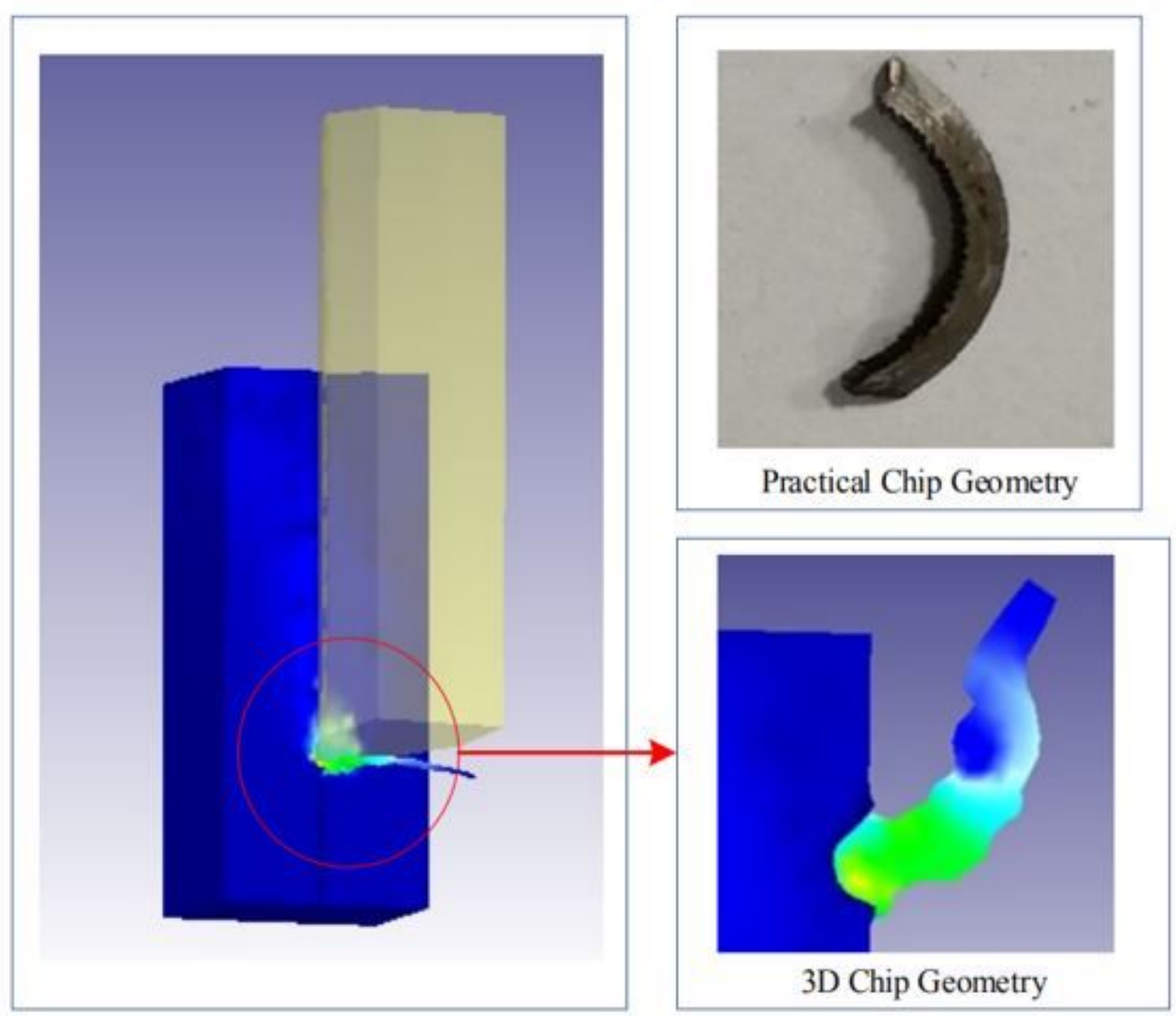

Figure 6

Comparison between simulation chip and actual workshop chip 


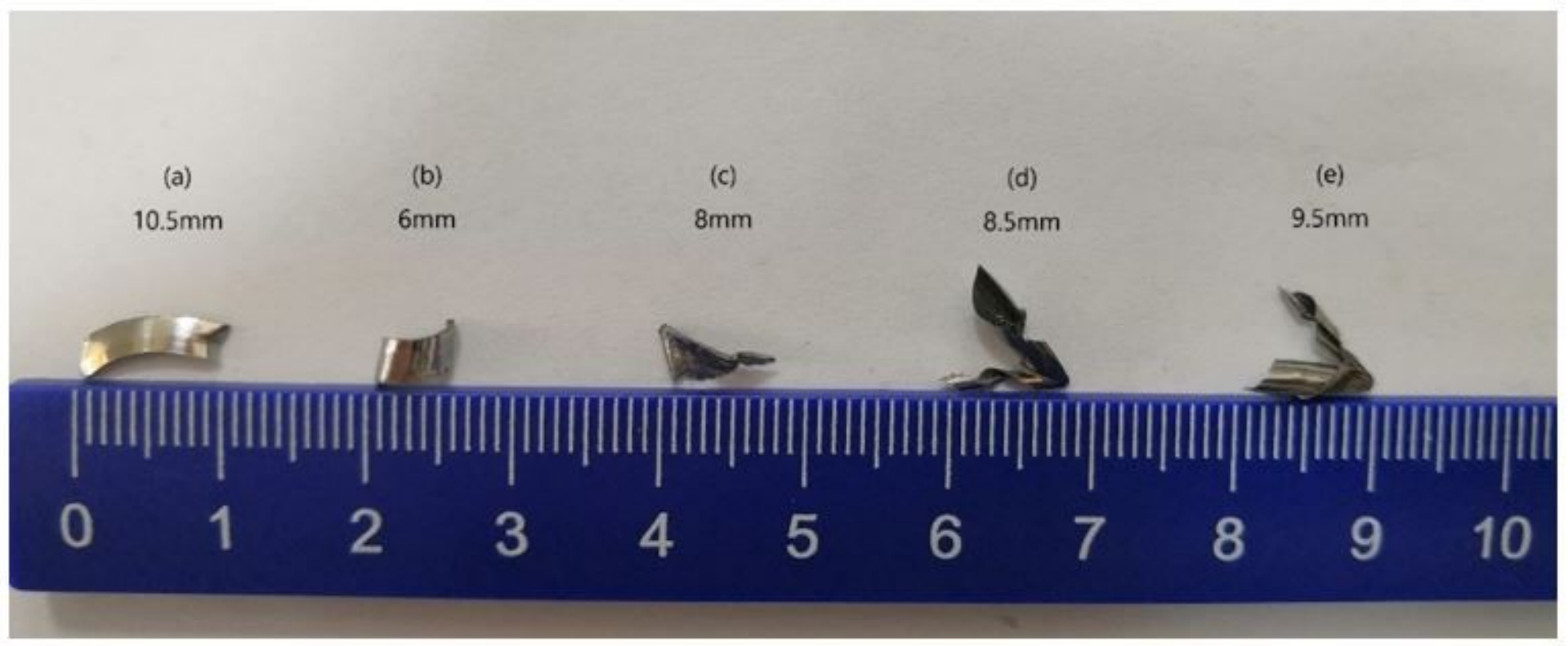

Figure 7

42CrMo gear ring actual gear shaping chip diagram

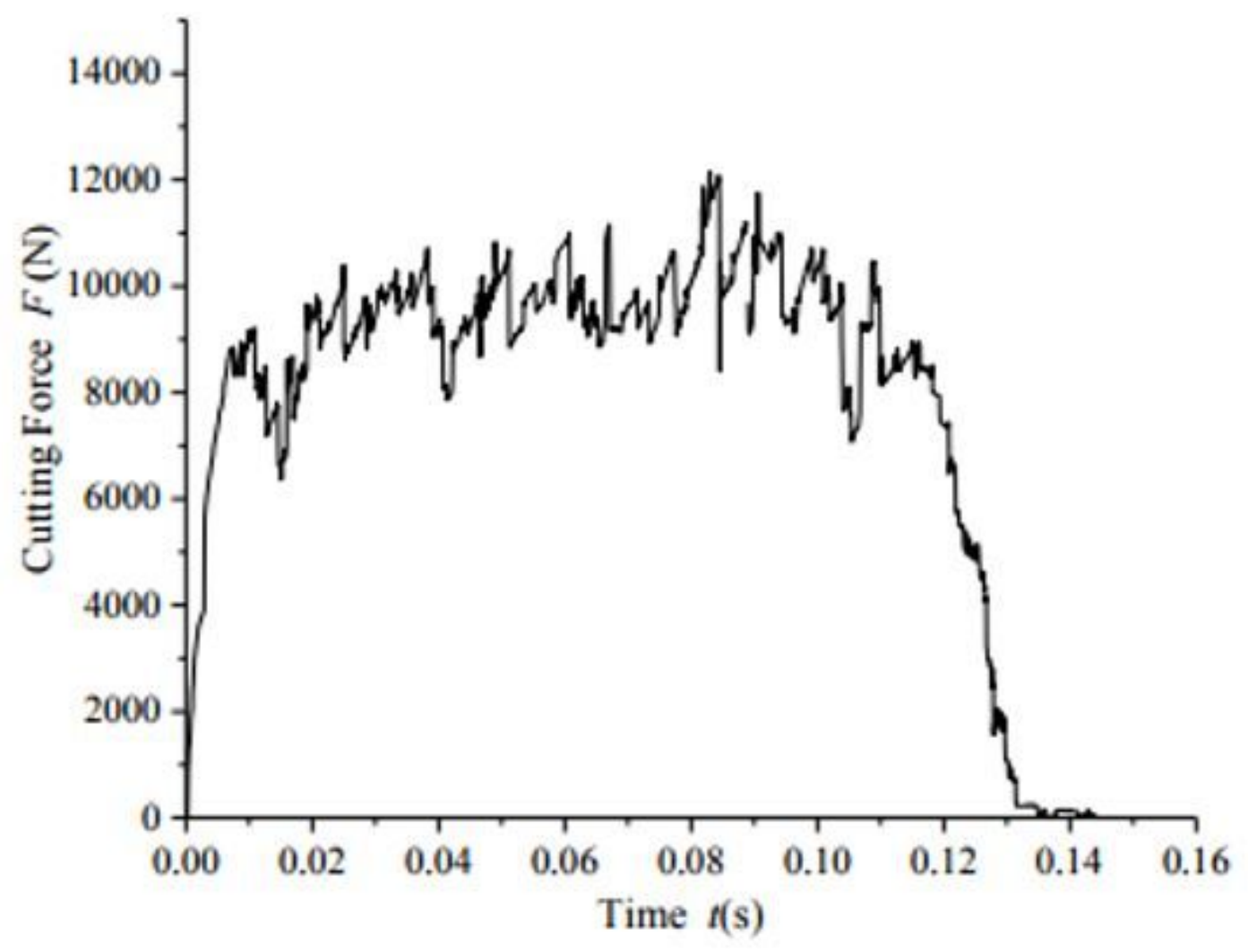

Figure 8

Main cutting force load 


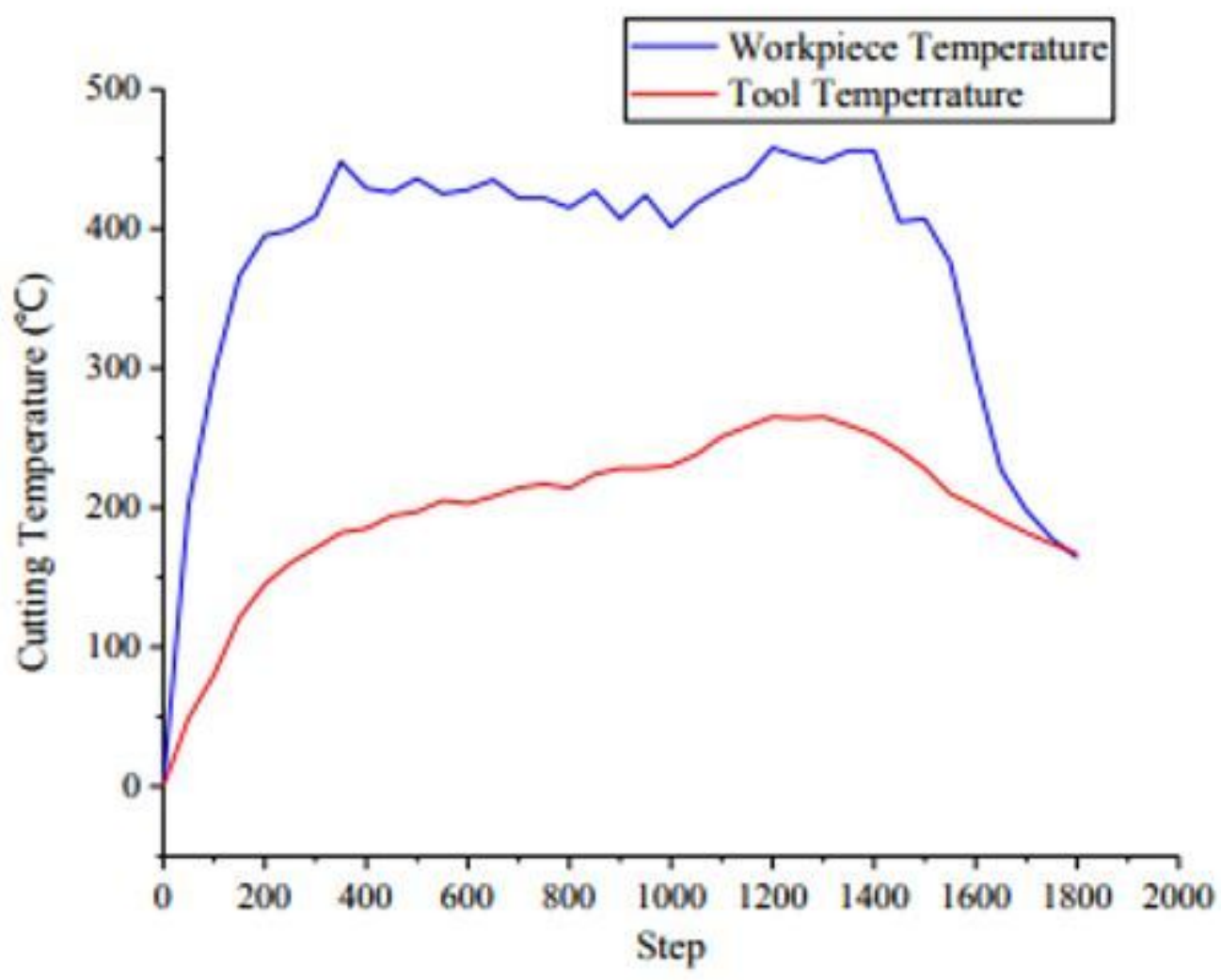

Figure 9

Simulated cutting temperature 

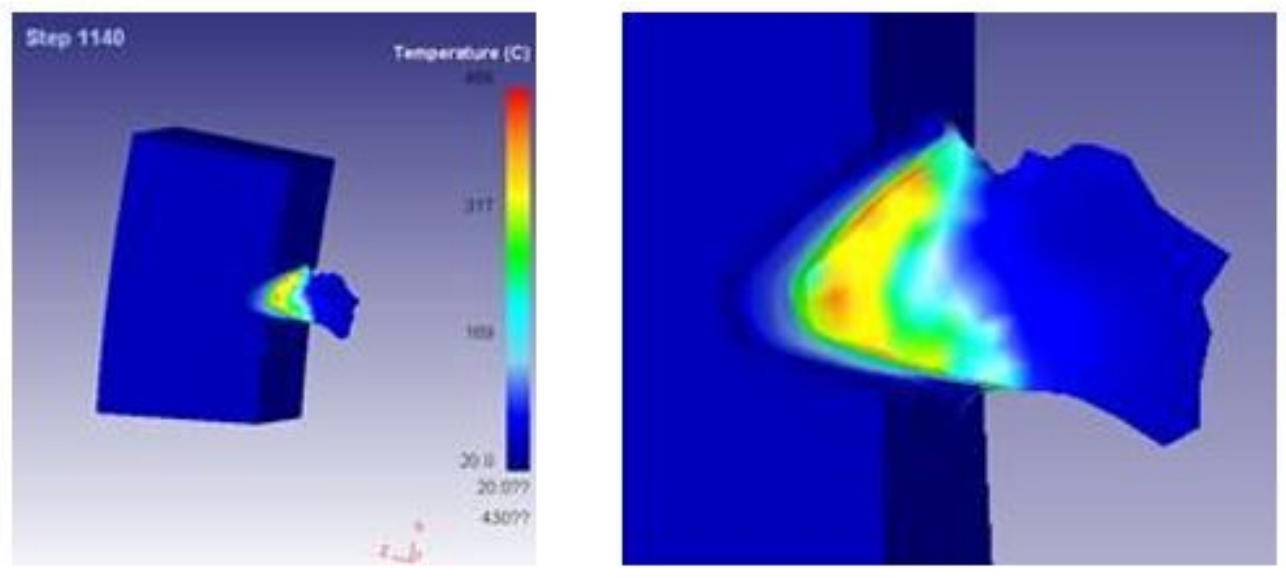

(a) Temperature distribution of workpiece
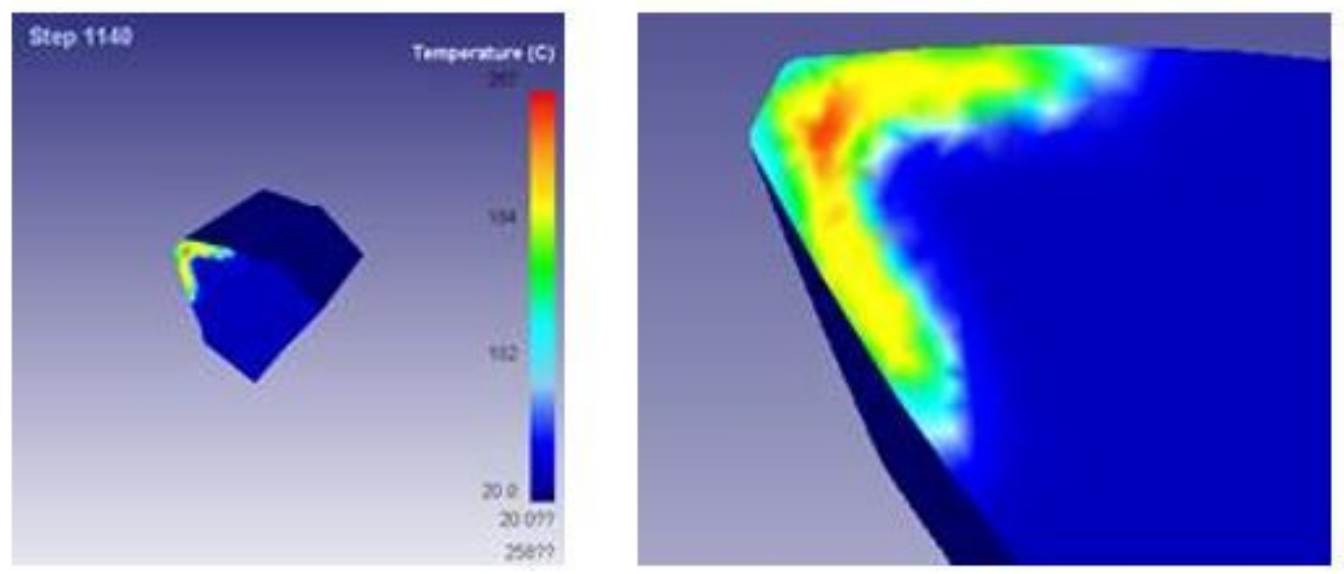

(b) Tool temperature distribution

Figure 10

Temperature distribution of workpiece and tool 


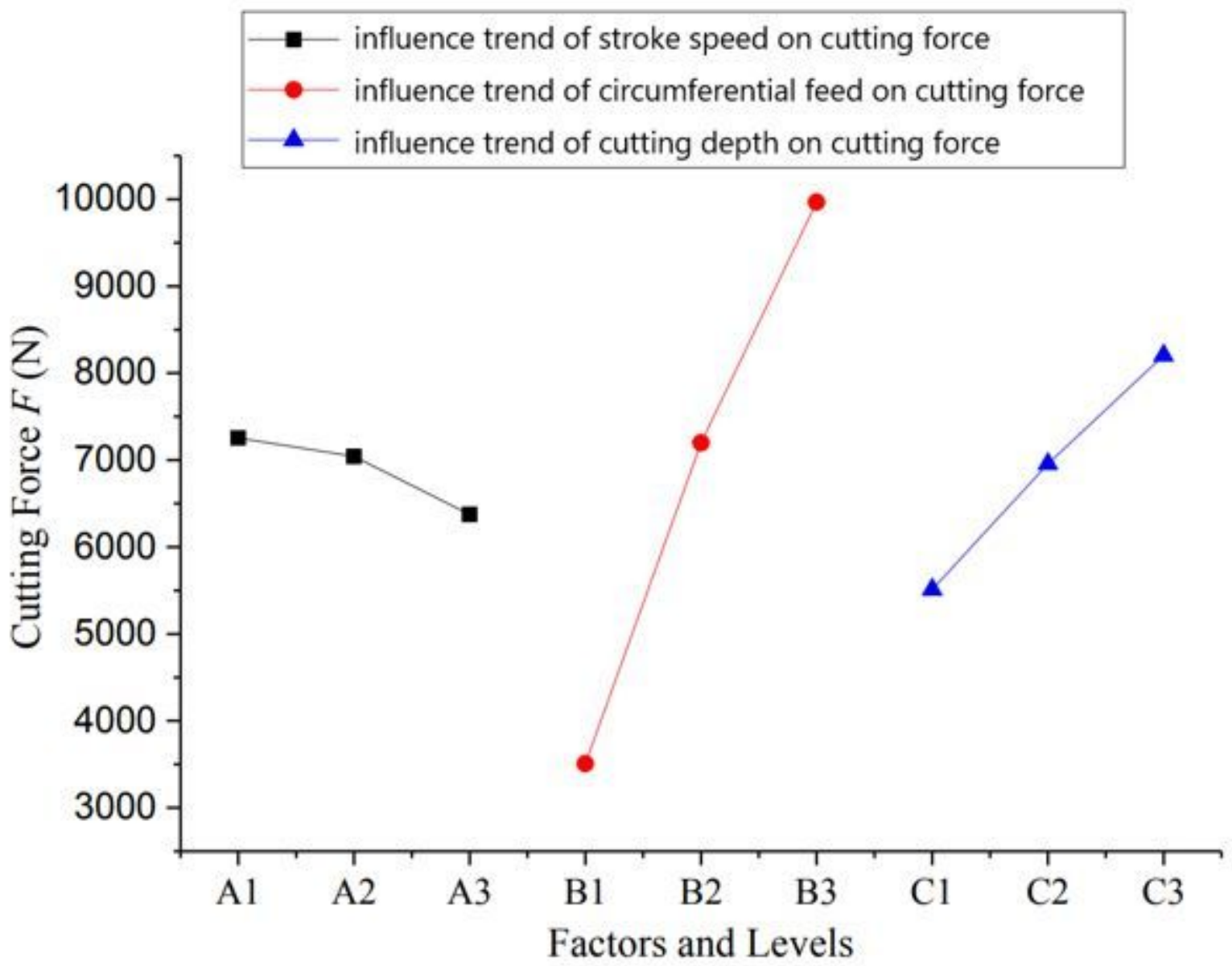

Figure 11

Influence trend of gear shaping cutting parameters on main cutting force

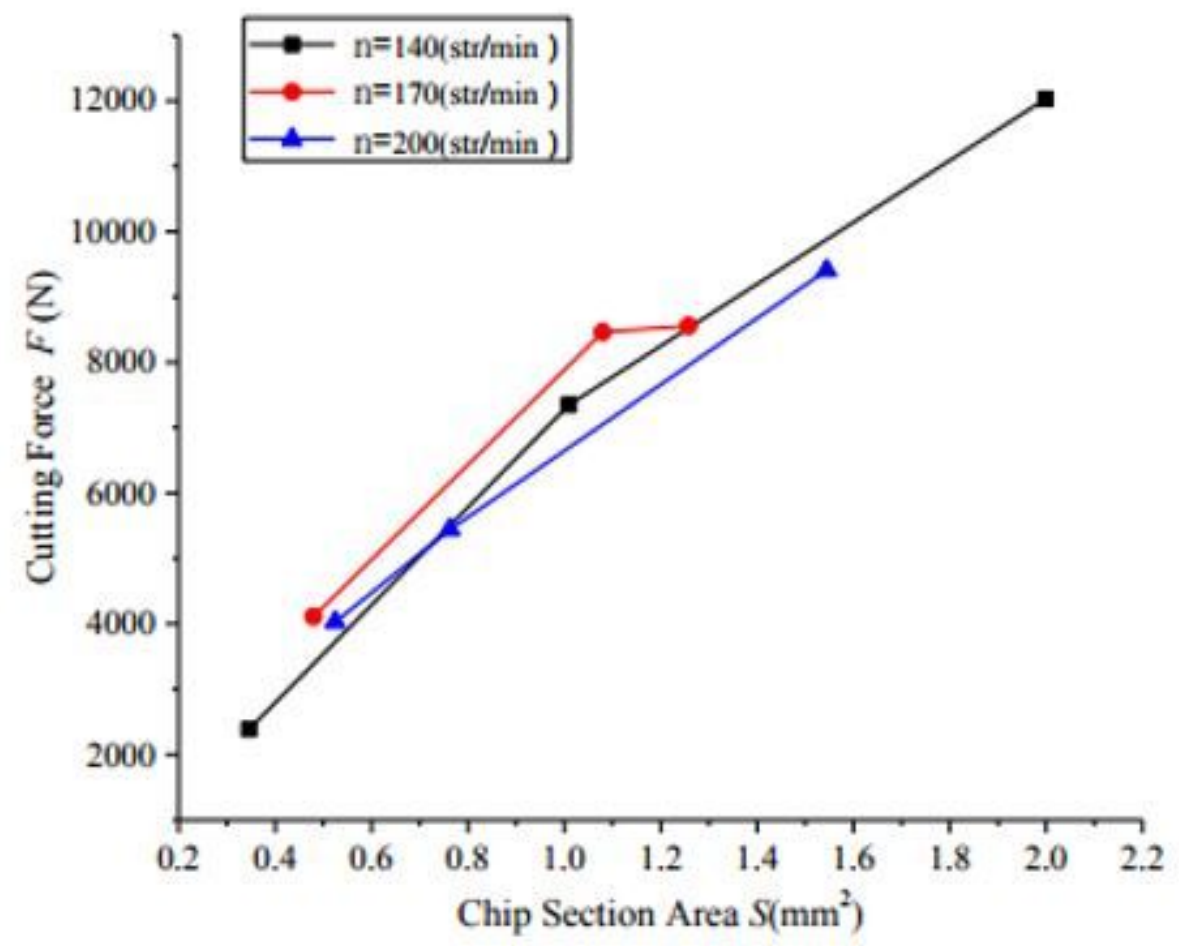


Figure 12

The relationship between chip section area and main cutting force

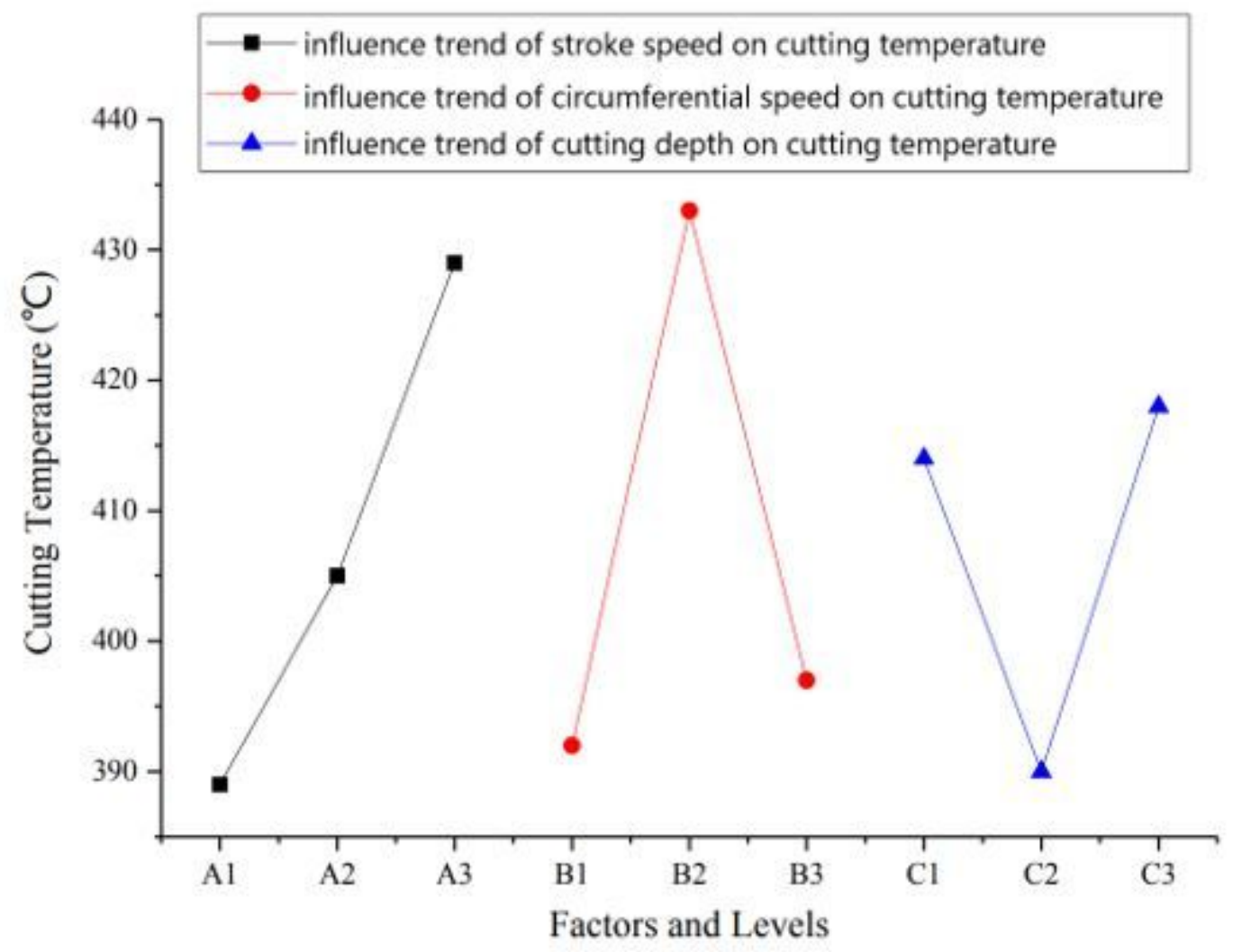

Figure 13

Influence trend of gear shaping cutting parameters on cutting temperature 


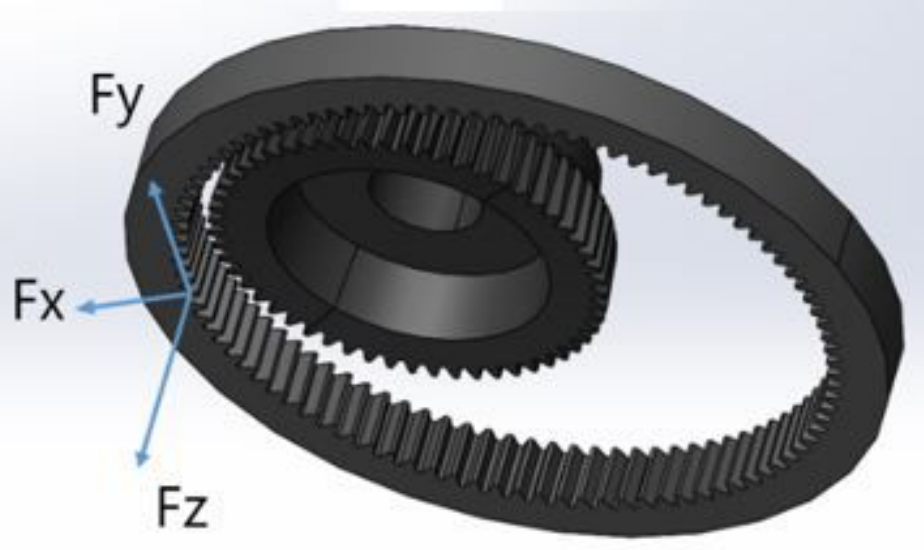

Figure 14

Force decomposition during gear shaping 


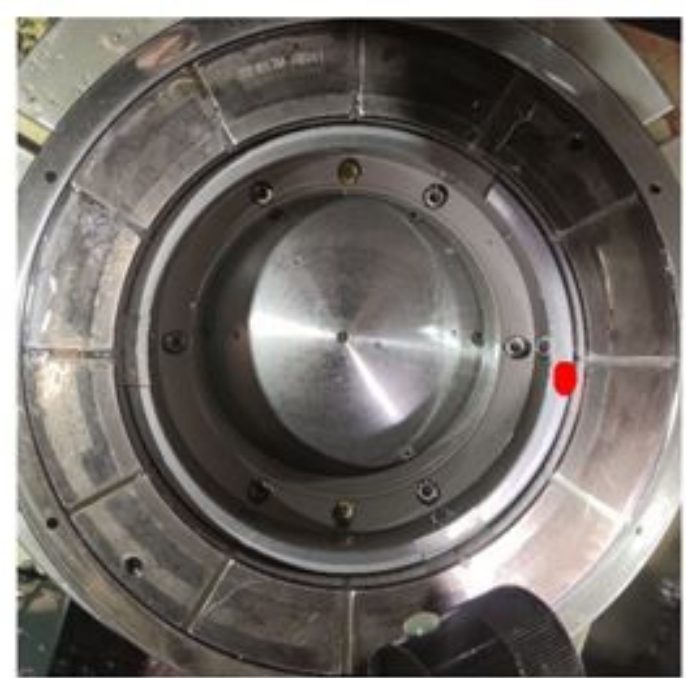

(a)

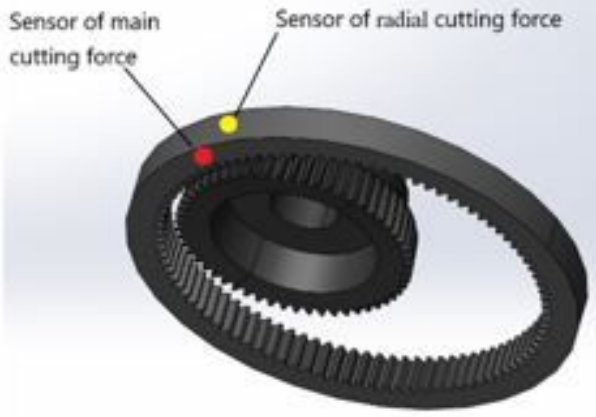

(c)

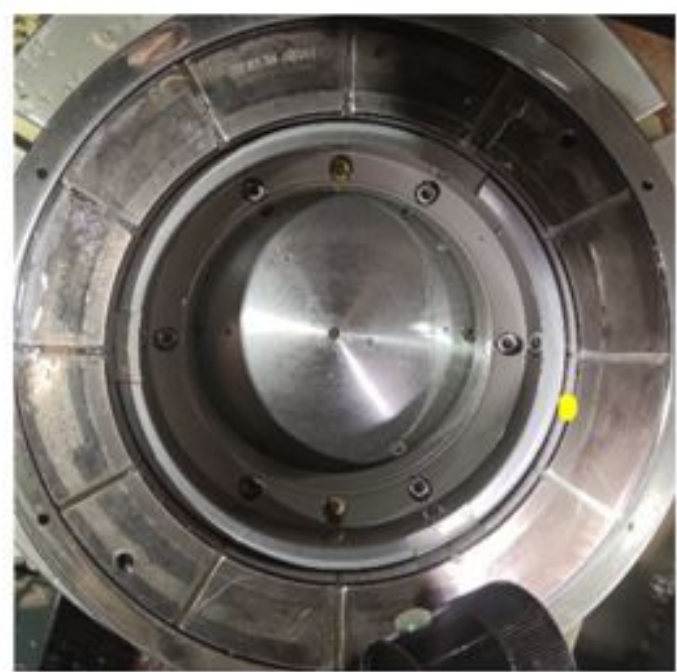

(b)

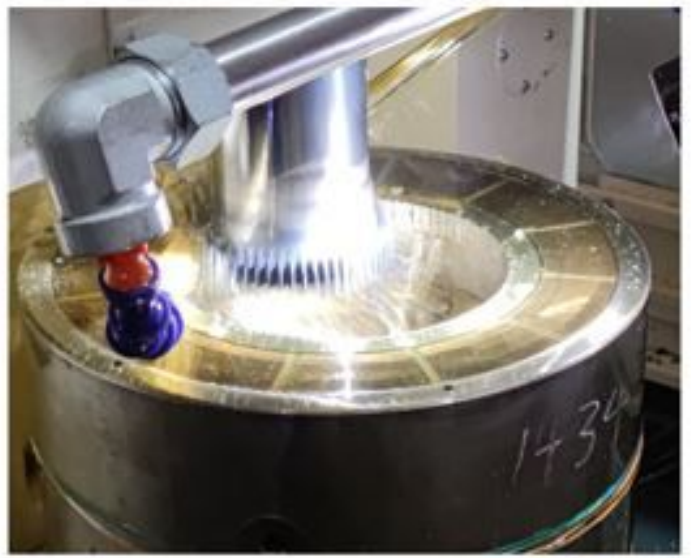

(d)

Figure 15

Relative position of membrane pressure sensor 

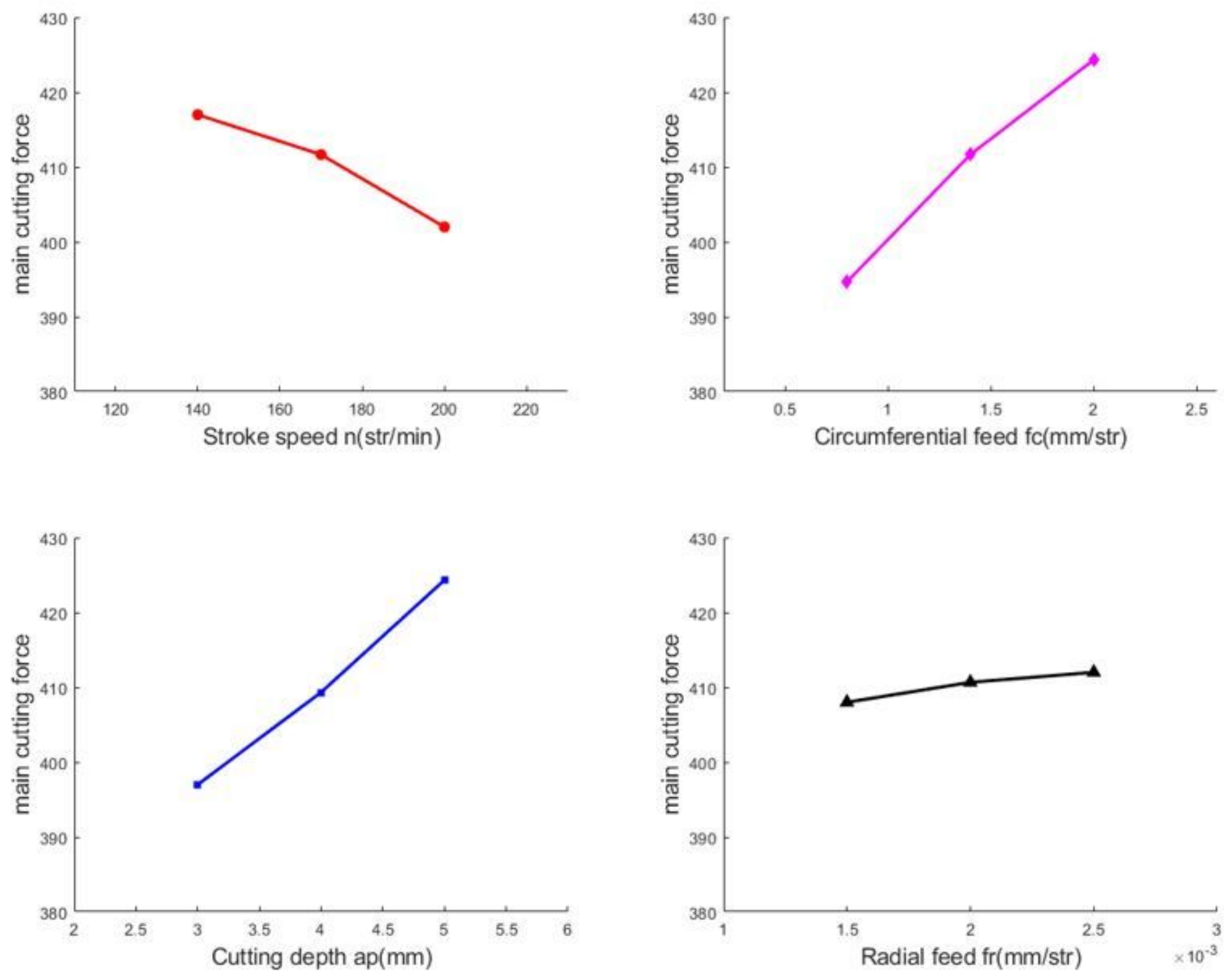

\section{Figure 16}

The influence trend of parameters on the main cutting force 

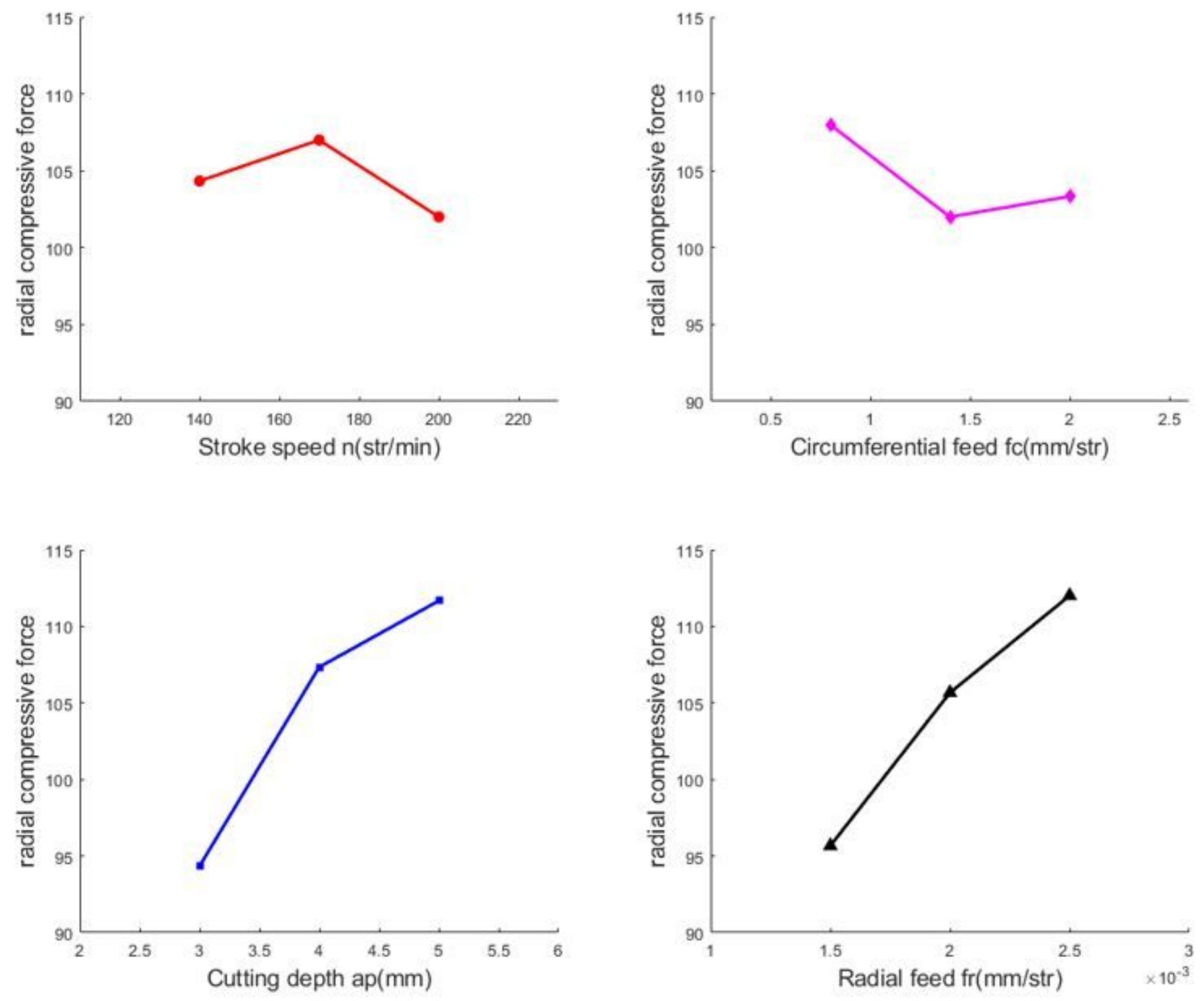

\section{Figure 17}

The influence trend of cutting parameters on radial cutting force 


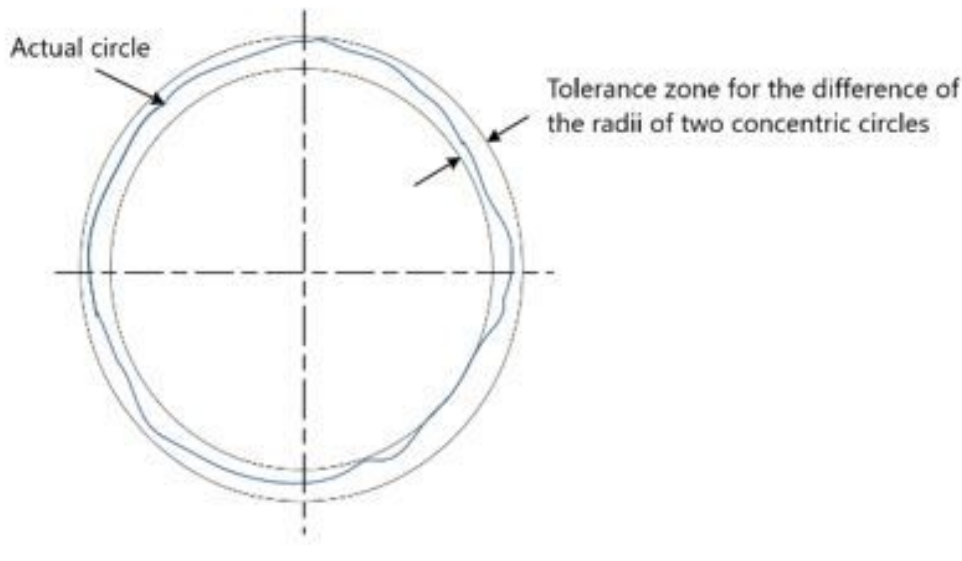

(a) Diagram of roundness

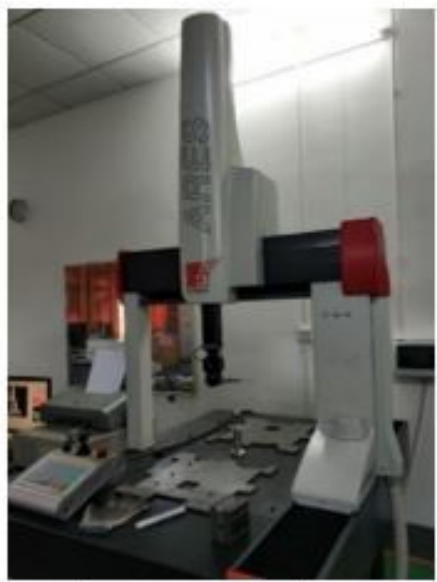

(b) COORD3 (Ares Series) CMM

Figure 18

Roundness and its measurement 

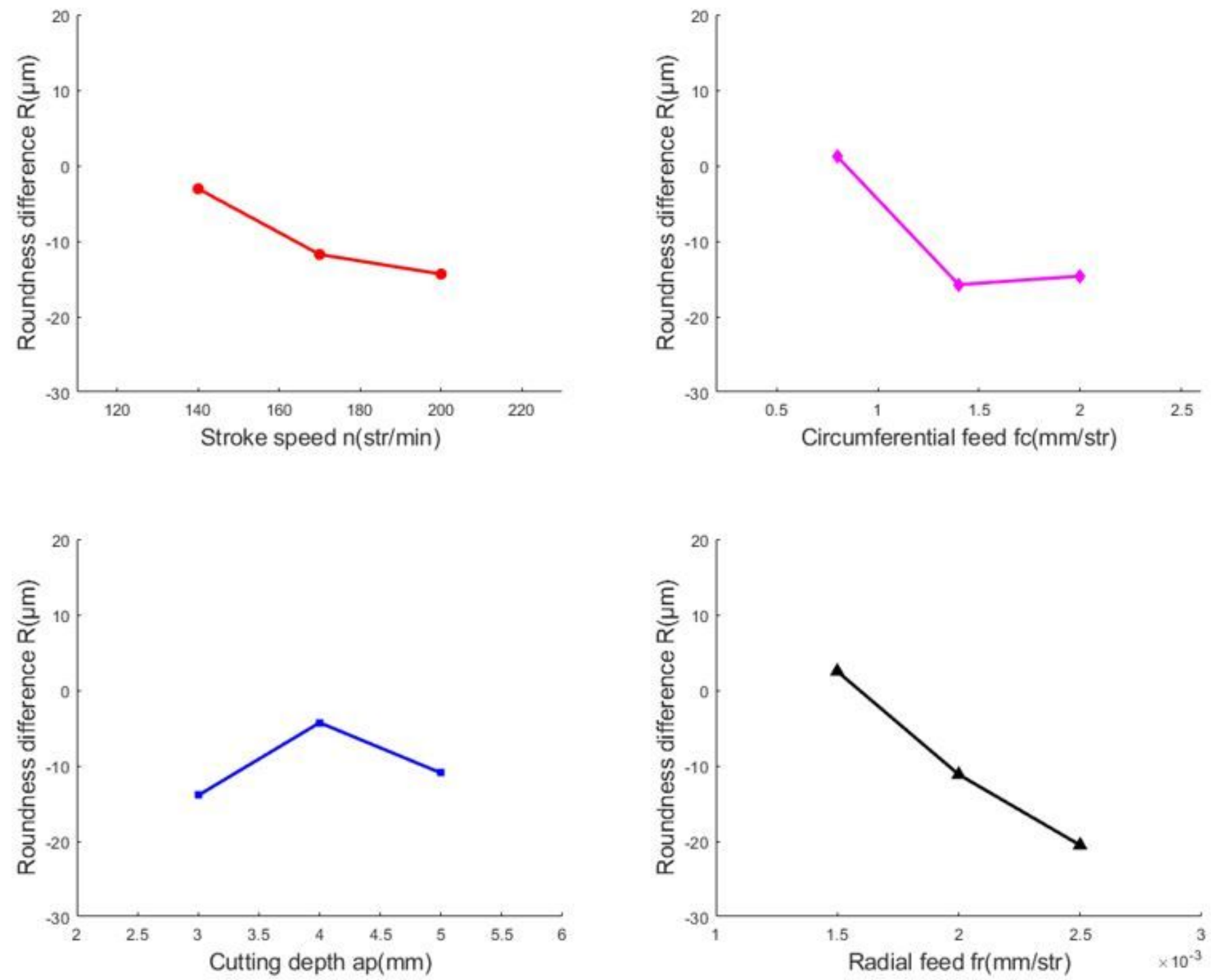

Figure 19

The influence trend of parameters on ring gear deformation 


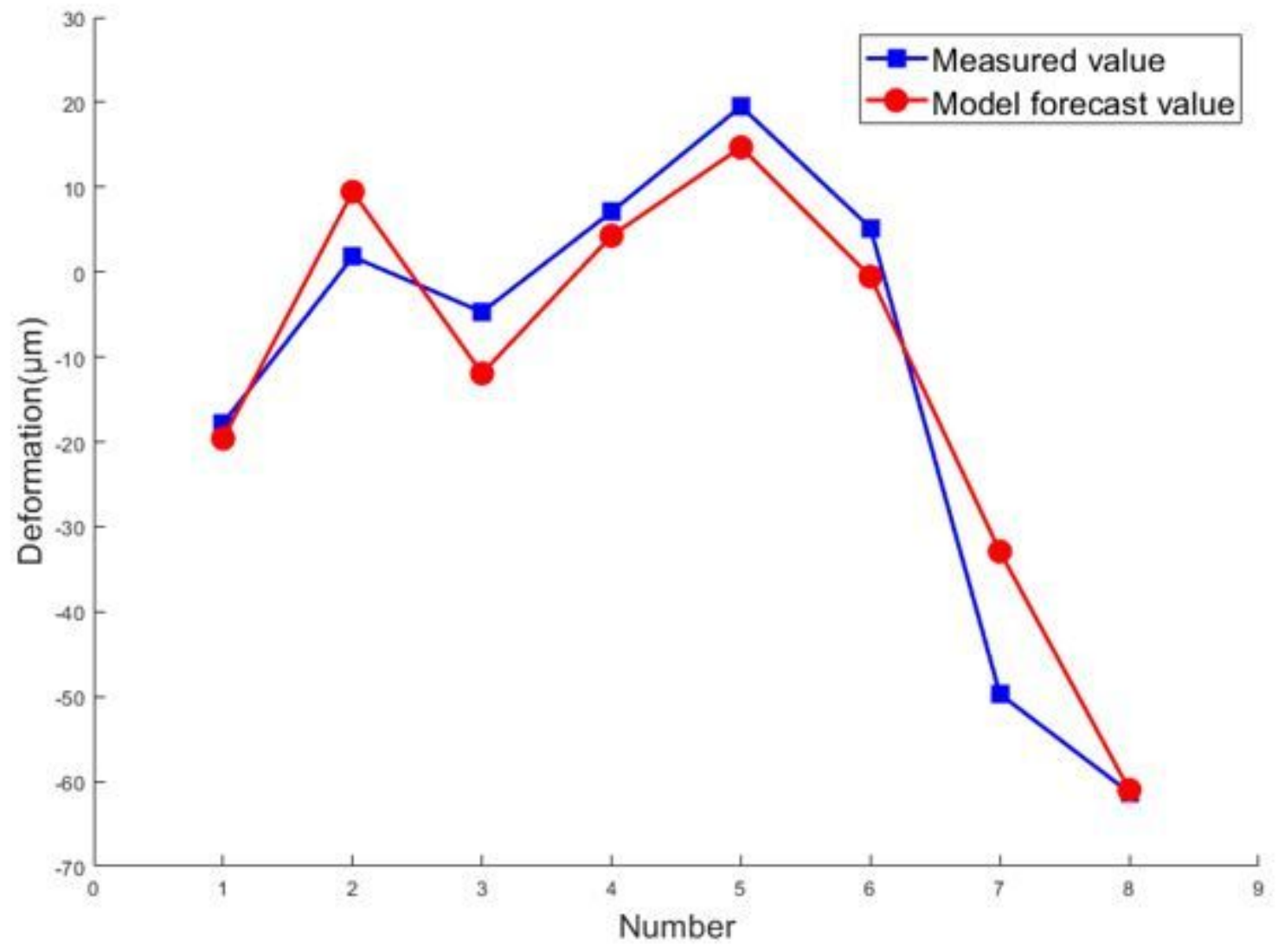

Figure 20

Fitting results of deformation model 